AperTO - Archivio Istituzionale Open Access dell'Università di Torino

\title{
On the Role of Morphology of CoFeO4 Spinel in Methanol Anaerobic Oxidation
}

\section{This is the author's manuscript}

Original Citation:

Availability:

This version is available http://hdl.handle.net/2318/116731

since 2015-12-16T16:04:04Z

Published version:

DOI:10.1021/jp304355d

Terms of use:

Open Access

Anyone can freely access the full text of works made available as "Open Access". Works made available under a Creative Commons license can be used according to the terms and conditions of said license. Use of all other works requires consent of the right holder (author or publisher) if not exempted from copyright protection by the applicable law. 


\section{(3.) \\ UNIVERSITÀ DEGLI STUDI DI TORINO}

This is an author version of the contribution published on:

Questa è la versione dell'autore dell'opera:

[The journal of Physical Chemistry C, 116, 2012, DOI: 10.1021/jp304355d]

The definitive version is available at:

La versione definitiva è disponibile alla URL:

[http://pubs.acs.org/doi/abs/10.1021/jp304355d] 


\section{On the role of morphology of $\mathrm{CoFeO}_{4}$ spinel in methanol anaerobic oxidation}

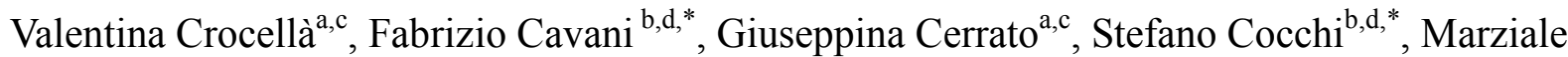
Comito $^{\mathrm{b}}$, Giuliana Magnacca ${ }^{\mathrm{a}, \mathrm{c}}$, Claudio Morterra ${ }^{\mathrm{a}, \mathrm{c}}$

${ }^{a}$ Dept. of Chemistry and NIS Centre of Excellence, Università di Torino, Via P. Giuria 7, 10125 Torino, Italy

${ }^{\mathrm{b}}$ Dipartimento di Chimica Industriale e dei Materiali, ALMA MATER STUDIORUM Università di Bologna, Viale Risorgimento 4, 40136 Bologna, Italy

${ }^{\mathrm{c}}$ Consortium INSTM (Florence), Research Unit of Torino University

${ }^{\mathrm{d}}$ Consortium INSTM (Florence), Research Unit of Bologna University

*fabrizio.cavani@unibo.it; stefano.cocchi8@unibo.it 


\begin{abstract}
A $\mathrm{CoFe}_{2} \mathrm{O}_{4}$ inverse spinel calcined at two different temperatures $\left(450^{\circ} \mathrm{C}\right.$ and $\left.750^{\circ} \mathrm{C}\right)$, in order to modulate the growth of the crystallites, has been employed in methanol anaerobic oxidation. A correlation between physico-chemical properties and catalytic performances of the material has been pursued. The study of both surface and bulk properties has been carried out by means of different experimental techniques, among which X-ray diffraction (XRD), transmission electron microscopy (TEM), and in situ FTIR spectroscopy. The FTIR study of both bulk and surface spectral features reveals that the calcination step is responsible for the different type of exposed surface sites, and as a consequence, for the different catalytic behaviour. As the use of the spinel as catalyst for methanol transformation into $\mathrm{H}_{2}$ necessarily implies a regeneration step with steam, in order to recover the oxidative capacity of the solid, both surface and bulk features of the reoxidized solids have been also studied. All results reveal that the two samples, originally morphologically quite different from one another, become very similar after just one redox cycle. Still, it has been also demonstrated that both used materials irreversibly modify their surface properties after the reduction/oxidation process.
\end{abstract}




\section{Introduction}

Alcohols, especially methanol and ethanol, are feeds for hydrogen production due to their high hydrogen to carbon $(\mathrm{H} / \mathrm{C})$ atomic ratios, ease of handling, mass production, and biomassderivability [1,2]. Because of these reasons, methanol steam reforming (MSR) for hydrogen production continues to be an active area of research [3-6]. When compared to other fuels, methanol presents both disadvantages and advantages; for instance, some drawbacks are its toxicity and miscibility with water, and the lower reformed hydrogen content compared to the other fuels. Even though the hydrogen energy density of methanol is much lower than that of typical hydrocarbon fuels (being however roughly the same when the stoichiometrically required water is considered), methanol has the advantage of producing low amount of $\mathrm{CO}$ during reforming, much less than the other fuels. Moreover, the absence of a $\mathrm{C}-\mathrm{C}$ bond facilitates the reforming at low temperatures $\left(200-300^{\circ} \mathrm{C}\right.$ ), and this limits coke formation (which is one of the main problem in hydrocarbons reforming reactions carried out at $400-500^{\circ} \mathrm{C}$ ). All this enables milder reaction platforms to extract hydrogen from alcohols. Finally, methanol is liquid, and biodegradable at atmospheric conditions. These peculiarities make methanol an interesting hydrogen-carrier fuel not only for portable and small power devices (eg, for PEM fuel-cells), but also for larger applications.

On the other hand, other methods can be employed for hydrogen production from methanol, eg., decomposition, partial oxidation and autothermal reforming [6]. The partial oxidation [7] has the advantages of being an exothermic reaction and, therefore, a higher reaction rate is expected, since the time needed to reach the working temperature from the cold start-up conditions should be shorter. In general, two different approaches are possible for methanol catalytic partial oxidation: direct and indirect. In the former, methanol reacts with substoichiometric amounts of oxygen (catalytic partial oxidation, CPO), in the latter total oxidation of methanol is combined with steamand/or $\mathrm{CO}_{2}$-reforming. $\mathrm{CPO}$ follows a complex mechanism: it has been proposed that different paths for methanol conversion, such as oxidation, steam-reforming, and decomposition may take 
place simultaneously [8-15]. $\mathrm{Cu}-\mathrm{ZnO}$ and $\mathrm{Pd}$ are the most active catalysts for methanol $\mathrm{CPO}$; different research groups have carried out detailed investigations on $\mathrm{Cu}-\mathrm{ZnO}$-based catalysts (see, for instance reference [7] and references therein) in which the activity and hydrogen selectivity are strictly related to $\mathrm{Cu}-\mathrm{Zn}$ interactions.

In regard to methanol decomposition, different catalysts are active in this reaction [16-20]. Besides $\mathrm{Cu}-\mathrm{ZnO}$ systems and group 10 and 11 metals (among which Ni and Pd have been the most widely studied [15]), a great deal of literature exists on methanol decomposition (including anaerobic oxidation) over Co or Fe oxide-based catalysts [21-25]. Cobalt has also been proposed as a very promising catalyst to replace noble metals for $\mathrm{H}_{2}$ production by steam reforming of ethanol $[26,27]$.

Fewer papers deal with Co-Fe spinels as catalysts for methanol decomposition [24]. Binary and ternary spinel ferrites can be employed as catalysts for reactions, such as oxidative dehydration of hydrocarbons, decomposition of alcohols and hydrogen peroxide, treatment of automobileexhausted gases, oxidation of various compounds, and phenol hydroxidation [28-39]. Moreover, these materials exhibit basic properties that make them active in phenolics methylation [36, 40-44]. It is also known that their physico-chemical properties and reactivity are affected by nature and distribution of the metal cations present in the structure. In turn, the latter can be influenced by preparation conditions [45-56].

This paper deals with the study of methanol reaction in presence of the $\mathrm{CoFe}_{2} \mathrm{O}_{4}$ spinel under anaerobic conditions, which finally turns out to be a combination of (anaerobic) methanol partial oxidation and decomposition. More in detail, it has been analyzed how the main physicochemical properties of the spinel affect its catalytic behavior and how bulk and surface features of the spinel change after methanol contact. 


\section{Experimental}

\section{Preparation and characterization of $\mathrm{CoFe}_{2} \mathrm{O}_{4}$ spinels}

$\mathrm{Co} / \mathrm{Fe} / \mathrm{O}$ mixed oxides with the inverse spinel structure were prepared as described in detail elsewhere [57]. Briefly, a coprecipitation of the mixed $\mathrm{Co} / \mathrm{Fe}$ oxohydrate was carried out by dropping an aqueous solution of $\mathrm{Fe}(1.0 \mathrm{M})$ and $\mathrm{Co}(0.5 \mathrm{M})$ nitrates to an aqueous solution of $\mathrm{NaOH}(0.8 \mathrm{M})$ at $40^{\circ} \mathrm{C}$, keeping the $\mathrm{pH} 11$ by $\mathrm{NaOH}$ controlled addition. Then, the solid was vacuum filtrated and washed to remove $\mathrm{Na}^{+}$and nitrates, and dried in air at $120^{\circ} \mathrm{C}$ overnight. After the synthesis, the material was calcined in air for $2 \mathrm{~h}$ at either $450^{\circ} \mathrm{C}$ or $750^{\circ} \mathrm{C}$ (samples termed as CF450 and CF750, respectively). Calcination temperature allows to control the crystallinity degree of the oxides and the overall particle size.

The crystalline structure and crystallite size of the $\mathrm{CoFe}_{2} \mathrm{O}_{4}$ were obtained by X-ray diffraction (XRD) using a Philips PW 1820 powder diffractometer operating at $40 \mathrm{kV}$ and $40 \mathrm{~mA}$, with Ni-filtered $\mathrm{Cu} \mathrm{K} \mathrm{K}_{\alpha}$ radiation $(\lambda=1.5418 \AA)$.

Surface areas were determined using a Sorpty 1700 Carlo Erba instrument, based on the BET single point method $\left(\mathrm{N}_{2}\right.$ adsorption at the temperature of liquid $\left.\mathrm{N}_{2}\right)$.

HR-TEM images were obtained with a JEOL 3010-UHR instrument (acceleration potential: 300kV; LAB6 filament). Samples were "dry" dispersed on lacey carbon Cu grids.

FTIR spectra in the mid-infrared region were obtained at $4 \mathrm{~cm}^{-1}$ resolution on a Bruker IFS113v spectrophotometer equipped with MCT cryodetector, and on a Bruker IFS 88 spectrometer with DTGS detector, when it was necessary to reach lower wavenumbers. All samples were examined either in situ in the form of self-supporting pellets of the material as such $\left(\sim 20 \mathrm{mg} \mathrm{cm}^{-2}\right)$, or (in air) mixed with a proper amount of $\mathrm{KBr}$ powder (1:10 weight ratio). The spectra of probe molecules adsorbed on sample pellets were obtained with the solid sample contained in a homemade quartz cell, equipped with $\mathrm{KBr}$ windows, connected to a conventional high-vacuum line (UHV) that allows samples activation and spectra acquisition on the materials of interest in strictly 
in situ conditions. Prior to spectroscopic analyses, sample pellets were preliminarily activated at $350^{\circ} \mathrm{C}$, either in vacuo or in oxidizing conditions in the presence of $\mathrm{O}_{2}$.

Far-infrared measurements were recorded at $2 \mathrm{~cm}^{-1}$ resolution on a Bruker Vertex 70 equipped with a Si beam splitter and a DTGS detector for far-IR region. Samples were examined in air in the form of self-supporting pellets mixed with a proper amount of paraffin wax. This material, unlike $\mathrm{KBr}$ powder, is transparent to IR radiation in the $400-100 \mathrm{~cm}^{-1}$ range.

When necessary, IR bands resolution was carried out using the FIT routine by Bruker, and imposing, for each mass-normalized spectrum, only the number of spectral components to be resolved, whereas all major spectral parameters (intensity, spectral position, half-band width, percent of Gaussian profile) were allowed to float freely.

\section{Reactivity experiments}

Reactivity experiments were carried out by loading $400 \mathrm{mg}$ of CF samples, shaped in particles with diameter ranging from 0.25 to $0.6 \mathrm{~mm}$, in fixed-bed quartz flow reactor. The bed temperature was measured by means of an axial thermocouple placed inside. The reaction was carried out by feeding continuously a stream of methanol vapors $(15.6 \mathrm{~mol} \%)$ and $\mathrm{N}_{2}$; the latter was also used as an internal standard; contact time was $0.25 \mathrm{~s}$. The reaction time was kept long enough to reach the maximum level of solid reduction that could be obtained at those reaction conditions. Some experiments were also carried out by feeding a steam-containing stream $\left(19 \%\right.$ steam in $\left.\mathrm{N}_{2}\right)$ over the reduced solid, in order to characterize the spent (reduced) solid after reoxidation; the contact time used for these experiments was $0.25 \mathrm{~s}$. Before tests, catalysts were pretreated in $\mathrm{N}_{2}$ flow at $450^{\circ} \mathrm{C}$ for $2 \mathrm{~h}$ in order to decompose carbonates.

Instantaneous yields of each C-containing product were calculated by referring the outlet molar flow of each reaction product to the inlet molar flow of methanol. In the case of $\mathrm{H}_{2}$ and $\mathrm{H}_{2} \mathrm{O}$ yields, the outlet molar yields were also referred to the inlet flow of methanol, dividing the obtained 
values by 2 . As the solid released $\mathrm{O}$ to form products, as long as complete reduction was achieved, and as coke or carbonaceous residues might accumulate on the solid during reaction, it was not possible to make neither an atomic balance on $\mathrm{O}$ atom nor on $\mathrm{C}$ atom. Therefore, it was carried out an instantaneous balance on $\mathrm{H}$ (the only species which was not contained in an accumulation term in material balances for the flow reactor), which allowed to calculate: (a) the instantaneous balance on $\mathrm{C}$ and hence the amount of $\mathrm{C}$ accumulating on catalyst (expressed with the term "coke"), and (b) the instantaneous balance on $\mathrm{O}$ and hence the amount of $\mathrm{O}$ released from the catalyst. Finally, the reduction degree of the solid was obtained.

An Agilent 3000A micro-GC was installed on-line, to monitor the concentration of each component in the effluent stream; the instrument was equipped with 3 columns: (a) a PlotQ column, carrier $\mathrm{N}_{2}$, for the separation of $\mathrm{CH}_{4}, \mathrm{CO}_{2}, \mathrm{H}_{2} \mathrm{O}$ and methanol; (b) a $\mathrm{OV} 1$ column, carrier $\mathrm{N}_{2}$, for the separation of $\mathrm{CO}_{2}$, formaldehyde, $\mathrm{H}_{2} \mathrm{O}$, methanol, methylformate, dimethylether, dimethoxymethane; (c) a Molecular Sieve 5A column, carrier Ar, for the separation of $\mathrm{H}_{2}, \mathrm{O}_{2}, \mathrm{~N}_{2}$, $\mathrm{CH}_{4}$, and $\mathrm{CO}$. A PlotU backflash column was installed in order to avoid $\mathrm{CO}_{2}$ and $\mathrm{H}_{2} \mathrm{O}$ poisoning in the third column.

\section{Results and Discussion}

\section{The effect of thermal annealing on bulk characteristics}

Table 1 summarizes the main physico-chemical features of the $\mathrm{CoFe}_{2} \mathrm{O}_{4}$ samples after a thermal treatment at two different temperatures, $450^{\circ} \mathrm{C}(\mathrm{CF} 450)$ and $750^{\circ} \mathrm{C}(\mathrm{CF} 750)$; the same samples were studied as catalysts for phenol gas-phase methylation with methanol in a previous work [57].

Both phase and crystallite size have been probed by powder XRD (Figure 1). The freshly precipitated and dried CF sample, and both calcined CF450 and CF750 samples reveal a series of 
reflections consistent with the $\mathrm{CoFe}_{2} \mathrm{O}_{4}$ inverse spinel structure; nevertheless, the different calcination temperature deeply affect the morphological features of the spinel. In fact, Scherrer's line broadening analysis on the (220), (311), (511) and (400) peaks reveal that the volume-averaged crystallite size increases from $15 \pm 2 \mathrm{~nm}$ for CF450 to $41 \pm 9 \mathrm{~nm}$ for CF750 (Table 1). Particle sintering and cristallites growth are accompanied by a significant decrease in surface area, from $70 \pm 14$ to $9 \pm 2 \mathrm{~m}^{2} \mathrm{~g}^{-1}$ (Table 1$)$.

HR-TEM microscopy of calcined samples further confirms what has been deduced by XRD analysis. TEM images (reported in Fig. 2) show crystalline particles with irregular shape with an average size of $\sim 10 \mathrm{~nm}$ for CF450 and of $\sim 25-30 \mathrm{~nm}$ for CF750, respectively; these values are in good agreement with those calculated on XRD patterns. In both cases, particles contours are smooth and roundish.

Infrared spectra of $\mathrm{KBr}$ pellets of the two fresh samples, run in the $900-400 \mathrm{~cm}^{-1}$ range, show the presence of an intense and broad band centred at $\sim 580 \mathrm{~cm}^{-1}$, ascribable to one of the typical vibrational modes of cobalt ferrites [58-61] (Fig. 3, top). In particular, this signal can be easily attributed to the Fe-O stretching vibrations in the tetrahedral complexes $\left[(\mathrm{Fe}-\mathrm{O})_{\mathrm{Th}}\right]$, whereas the $\mathrm{Fe}-\mathrm{O}$ and $\mathrm{Co}-\mathrm{O}$ vibrations in the octahedral complexes cannot be observed, as it is expected to be located at wavenumbers lower than $400 \mathrm{~cm}^{-1}$ (which is the "cut-off" of $\mathrm{KBr}$, present in both powder pellets and optics) [59-61]. For what concerns the fresh CF450 catalyst [solid line in section (a) of Fig. 3, top] it is possible to distinguish two different and heavily overlapped signals, located at $\sim 620$ and $\sim 587 \mathrm{~cm}^{-1}$, respectively, both ascribable to $(\mathrm{Fe}-\mathrm{O})_{\mathrm{Th}}$ vibrations. In the case of the CF750 sample, that possesses a much lower SSA with respect to the CF450 material, an asymmetric signal ascribable to the presence of $\mathrm{Fe}^{3+}$ in tetrahedral sites is evident in the spectrum at $\sim 580 \mathrm{~cm}^{-1}$ [solid line in section (b) of Fig. 3, top]; the different position of this signal for the two samples can be probably attributed to the changed (increased) particles size, caused by sintering phenomena. 
In order to better evidence the above mentioned changes of the $(\mathrm{Fe}-\mathrm{O})_{\mathrm{Th}}$ vibrations before and after the calcination step a computer-assisted band resolution has been carried out. Band resolved spectra in the $800-500 \mathrm{~cm}^{-1}$ spectral range of CF450 and CF750 [spectral sets I in section (a) and (b) of Fig. 3, bottom] point out the presence, in each band envelope, of two main components ascribable to the surface fraction of $(\mathrm{Fe}-\mathrm{O})_{\mathrm{Th}}$ modes (broad and asymmetric component at higher- $v$, named $\mathrm{S}_{(\mathrm{Th})}$ in the figure; this spectral component is made up of two symmetric subcomponents of fairly different intensity, not reported in the band-resolved spectra for the sake of simplicity, centred at 707 and $640 \mathrm{~cm}^{-1}$, respectively) and to the bulk $(\mathrm{Fe}-\mathrm{O})_{\mathrm{Th}}$ vibrations (symmetric band at lower- $v$, named $\mathrm{B}_{(\mathrm{Th})}$ in the figure). It is possible to observe that the $\mathrm{S}_{(\mathrm{Th})} / \mathrm{B}_{(\mathrm{Th})}$ integrated intensity ratio turns out to be appreciably different, depending on the calcination temperature. The $\mathrm{S}_{(\mathrm{Th})} / \mathrm{B}_{(\mathrm{Th})}$ integrated intensity ratio is lower for the material calcined at higher temperature: it is 0.85 for CF450, and drops to 0.6 for CF750. This result is not surprising, being the specific surface area of the material considerably reduced in the latter case.

As mentioned above, the $\mathrm{Fe}-\mathrm{O}$ and $\mathrm{Co}-\mathrm{O}$ vibrations in the octahedral complexes $\left[(\mathrm{Fe}-\mathrm{O})_{\mathrm{Oh}}\right.$ and $(\mathrm{Co}-\mathrm{O})_{\mathrm{Oh}}$ ] are expected to be located at wavenumbers lower than $400 \mathrm{~cm}^{-1}$ [58-61]. For this reason, spectra of CF450 and CF750 samples have been collected also in the far-IR region, as shown in Fig. 4 (top). In both section (a) and (b) of Fig. 4 (top), two distinct band envelopes are evident in the $600-200 \mathrm{~cm}^{-1}$ range, centred at $\sim 580 \mathrm{~cm}^{-1}$ and $\sim 360 \mathrm{~cm}^{-1}$, respectively. The former envelope has been attributed above to $(\mathrm{Fe}-\mathrm{O})_{\mathrm{Th}}$ vibrations, whereas the latter one can be ascribed to both $(\mathrm{Fe}-\mathrm{O})_{\mathrm{Oh}}$ and $(\mathrm{Co}-\mathrm{O})_{\mathrm{Oh}}$ vibrational modes $[60,61]$. In the case of the CF450 catalyst [solid line in section (a) of Fig. 4, top] it is possible to distinguish two severely overlapped signals, approximately located at $\sim 415$ and $\sim 360 \mathrm{~cm}^{-1}$, respectively; as in the case of the $(\mathrm{Fe}-\mathrm{O})_{\mathrm{Th}}$ modes, the high- $v$ signal component can be ascribed to a surface fraction of both $(\mathrm{Fe}-\mathrm{O})_{\mathrm{Oh}}$ and $(\mathrm{Co}-\mathrm{O})_{\mathrm{Oh}}$ vibrations. Also for the CF750 sample, a complex envelope is evident in the spectrum at $\sim 368 \mathrm{~cm}^{-1}$ 
[section (b)], however the shoulder at higher- $v\left(\sim 415 \mathrm{~cm}^{-1}\right)$ is far less evident than in the case of the CF450 catalyst, confirming the main surface character of this spectral component.

All the previous considerations can be confirmed by observing the band-resolved spectra reported in Fig. 4(bottom). In the case of the octahedral complexes vibrational modes, three different components can be observed. Besides the $\mathrm{Fe}^{3+}$ ions in octahedral sites, $\mathrm{Co}^{2+}$ ions are also present in octahedral sites. As anticipated above, the higher- $v$ component (termed $\mathrm{S}_{(\mathrm{Oh})}$ ) can be ascribed to the surface fraction of both $(\mathrm{Fe}-\mathrm{O})_{\mathrm{Oh}}$ and $(\mathrm{Co}-\mathrm{O})_{\mathrm{Oh}}$ modes, whereas the other two signals located at $\sim 370 \mathrm{~cm}^{-1}$ and $\sim 310 \mathrm{~cm}^{-1}$ (termed $\mathrm{B}_{\mathrm{Fe}(\mathrm{Oh})}$ and $\left.\mathrm{B}_{\mathrm{Co}(\mathrm{Oh})}\right)$ are ascribable to $(\mathrm{Fe}-\mathrm{O})_{\mathrm{Oh}}$ and $(\mathrm{Co}-$ O) $)_{\mathrm{Oh}}$ bulk vibrations, respectively [60]. Also in this case, the $\mathrm{S}_{(\mathrm{Oh})} / \mathrm{B}_{(\mathrm{Oh})}$ integrated intensity ratio (where $\mathrm{B}_{(\mathrm{Oh})}$ comprehends both $\mathrm{B}_{\mathrm{Fe}(\mathrm{Oh})}$ and $\mathrm{B}_{\mathrm{Co}(\mathrm{Oh})}$ ) depends on the calcination temperature: it decreases from 0.28 for CF450 to 0.09 for CF750, confirming the above speculations about the surface/bulk nature of the various components.

The IR spectroscopic assignment above reported can be confirmed also considering some crystallographic considerations [57]. In $\mathrm{CoFe}_{2} \mathrm{O}_{4}$ inverse spinel, the (111) plane exposes either tetrahedral $\mathrm{Fe}^{3+}$ or octahedral $\mathrm{Co}^{2+} / \mathrm{Fe}^{3+}$ sites; on the other hand, the (100) face can expose a mixture of both octahedral $\mathrm{Co}^{2+} / \mathrm{Fe}^{3+}$ and tetrahedral $\mathrm{Fe}^{3+}$ sites or just octahedral $\mathrm{Co}^{2+} / \mathrm{Fe}^{3+}$ sites. The equilibrium structure of small spinel clusters is likely to expose (111) and (110) faces, whereas larger spinel clusters should be based on a (100) terminated structure. In ref 57, it was reported how the surface composition of these oxide nanoparticles changed with their crystallite size (which is a consequence of the calcination temperature), with Fe content (calculated by XPS Co/Fe ratio): these features affected the crystallographic planes exposed. In that paper, the presence of highly reducible species in crystallites of smaller dimension was attributed to the reduction of the tetrahedral $\mathrm{Fe}^{3+}$ terminated (111) faces. In this work, infrared spectra provided further useful information: the higher is the calcination temperature, the lower is the general $\mathrm{S} / \mathrm{B}$ integrated intensity ratio. This phenomenon is ascribable to the lower contribution of surface sites, due to the increased crystallite 
size, consequence of the sintering process. As expected, CF750 exhibits a lower amount of both surface tetrahedral $\left(\mathrm{Fe}^{3+}\right)$ and surface octahedral $\left(\mathrm{Co}^{2+} / \mathrm{Fe}^{3+}\right)$ sites, due to its drastically lower surface area. As reported above, the S/B integrated intensity ratio decreases for both tetrahedral and octahedral complexes on passing from CF450 to CF750: in particular, the $\mathrm{S}_{(\mathrm{Th})} / \mathrm{B}_{(\mathrm{Th})}$ ratio decreases of $\sim 20 \%$ (from 0.85 to 0.59 ), whereas the $\mathrm{S}_{(\mathrm{Oh})} / \mathrm{B}_{(\mathrm{Oh})}$ one decreases of $\sim 70 \%$ (from 0.28 to 0.09 ). It can be preliminary concluded that, during the calcination step at the highest temperature, a definitely larger amount of octahedral $\left(\mathrm{Co}^{2+} / \mathrm{Fe}^{3+}\right)$ sites with respect to tetrahedral $\left(\mathrm{Fe}^{3+}\right)$ ones is removed from the surface.

\section{Anaerobic oxidation of methanol}

Figure 5 (top) plots the conversion of methanol and the yield to the various products as a function of the time-on-stream (tos), at the temperature of $300^{\circ} \mathrm{C}$, for the CF450 sample; the bottom figure displays the detail of the initial 50 min tos. Products were $\mathrm{CO}, \mathrm{CO}_{2}$ and $\mathrm{H}_{2}$, with minor amounts of $\mathrm{CH}_{4}$ and $\mathrm{H}_{2} \mathrm{O}$; the amount of coke formed was determined by means of the instantaneous $\mathrm{C}$ balance (see Experimental for details). Oxygenated products formed in very low amount, as detailed for each "Zone" (see below).

Figure 6 plots the $\mathrm{O}$ balance as a function of tos; a value of $\mathrm{O}$ balance higher than $100 \%$ indicates that the overall $\mathrm{O}$ content in the products was higher than that fed to the reactor (i.e., contained in methanol), since a certain amount of $\mathrm{O}$ was provided by the solid. This allows calculating the spinel reduction degree, which is also plotted in Figure 5.

These data highlight that the amount of each product was greatly affected by the degree of metal oxide reduction. In particular, combining the results of Figures 5 and 6, it was possible to distinguish different zones, during which the spinel undergoes a progressive reduction by methanol:

During the early $22 \mathrm{~min}$ tos (Zone I), the conversion of methanol increases slowly from $13 \%$ to $19 \%$. The main products are $\mathrm{H}_{2}$ and $\mathrm{CO}_{2}$, with a small amount of coke. The formation of $\mathrm{CO}$ and 
$\mathrm{CH}_{4}$ (which is very limited in the early minutes) is also evident in Zone I, together with the increase of $\mathrm{H}_{2}$ and a slight decrease of coke.

The reactions involved in Zone I are:

$$
\begin{aligned}
& \mathrm{CH}_{3} \mathrm{OH}+\mathrm{Me}^{\mathrm{n}+} \mathrm{O} \rightarrow \mathrm{CO}_{2}+2 \mathrm{H}_{2}+\mathrm{Me}^{(\mathrm{n}-2)+} \\
& \mathrm{CH}_{3} \mathrm{OH}+\mathrm{Me}^{(\mathrm{n}-2)+} \rightarrow \mathrm{C}+2 \mathrm{H}_{2}+\mathrm{Me}^{\mathrm{n}+} \mathrm{O} \\
& \mathrm{CH}_{3} \mathrm{OH} \rightarrow \mathrm{CO}+2 \mathrm{H}_{2} \\
& \mathrm{C}+2 \mathrm{H}_{2} \rightarrow \mathrm{CH}_{4}
\end{aligned}
$$

It is possible to exclude methane formation from $\mathrm{CO}$ and $\mathrm{CO}_{2}$ hydrogenation because both should produce $\mathrm{H}_{2} \mathrm{O}$, which does not form in Zone I, but in the very early minutes. Alternatively, the formation of coke might derive from Boudouard reaction:

$$
2 \mathrm{CO} \rightarrow \mathrm{CO}_{2}+\mathrm{C}
$$

However, this reaction should contribute less (at least in Zone I), because only a small amount of $\mathrm{CO}$ forms at the beginning of the process.

Moreover, the contribution from the total combustion of methanol reaction (reported below as reaction 6) also should be very low, since small amounts of water formed during the very early minutes of reaction:

$$
\mathrm{CH}_{3} \mathrm{OH}+2 \mathrm{Me}^{\mathrm{n}+} \mathrm{O} \rightarrow \mathrm{CO}_{2}+2 \mathrm{H}_{2} \mathrm{O}+2 \mathrm{Me}^{(\mathrm{n}-2)^{+}}
$$

In Zone I, the formation of oxygenated products is also observed, specifically the following: (i) methylformate (initial yield $0.11 \%$, which becomes nil after 4 min tos); (ii) dimethoxymethane (initial yield $0.07 \%$, nil after 4 min tos); (iii) formaldehyde (initial yield $0.01 \%$, nil after 4 min tos); and (iv) formic acid (initial yield $0 \%$, and then increasing up to $0.03 \%$ at the end of Zone I). Figure 6 shows that, in Zone I, the O released from the spinel decreases, probably because, at this stage, reaction 1 is inhibited, as well as the reaction of the light oxygenated compounds formation (formaldehyde, methylformate, etc.). 
During the period 22-100 min tos (Zone II), the yields of $\mathrm{CO}$ and $\mathrm{H}_{2}$ show a very similar rapid raise. Also, methanol conversion follows the same trend. This implies that the reactions responsible for the transformation of methanol into $\mathrm{CO}$ and $\mathrm{H}_{2}$ occur in presence of active sites, whose surface concentration increases during the exposure to the reactants stream (for example, on the $\mathrm{Me}^{(\mathrm{n}-2)+}$ sites generated by reaction (1)); also, $\mathrm{CO}_{2}$ forms during Zone II.

The main reactions involved in Zone II are:

$$
\begin{aligned}
& \mathrm{CH}_{3} \mathrm{OH} \rightarrow \mathrm{CO}+2 \mathrm{H}_{2} \\
& \mathrm{CH}_{3} \mathrm{OH}+\mathrm{Me}^{\mathrm{n}+} \mathrm{O} \rightarrow \mathrm{CO}_{2}+2 \mathrm{H}_{2}+\mathrm{Me}^{(\mathrm{n}-2)+}
\end{aligned}
$$

Reaction (1) is responsible for the increase of $\mathrm{O}$ release from the solid (Figure 6). Finally, coke amount also increases in Zone II, due to a raising contribution of reaction (2) or reaction (5):

$$
\begin{aligned}
& \mathrm{CH}_{3} \mathrm{OH}+\mathrm{Me}^{(\mathrm{n}-2)+} \rightarrow \mathrm{C}+2 \mathrm{H}_{2}+\mathrm{Me}^{\mathrm{n}+} \mathrm{O} \\
& 2 \mathrm{CO} \rightarrow \mathrm{CO}_{2}+\mathrm{C}
\end{aligned}
$$

This might explain the simultaneous increase of $\mathrm{CO}_{2}$ and $\mathrm{C}$ yields, even if reaction 5 does not take into account the increase of $\mathrm{O}$ release from spinel. Moreover, $\mathrm{O}$ release from material can be responsible of oxygenated compounds formation, such as formic acid, whose yield increases from $0.03 \%$ (after $22 \mathrm{~min}$ tos) to $0.16 \%$ (after $100 \mathrm{~min}$ tos), and methyformate, which exhibits a constant yield around to $0.01 \%$.

During the period 100-210 min tos (Zone III), methanol conversion increases and finally reaches the maximum value of $88 \%$; both coke and $\mathrm{CO}_{2}$ yields increase (the latter more distinctly than the former, apparently because of the overlapping of two different contributions), whereas the CO yield decreases from $53 \%$ at $100 \mathrm{~min}$ tos down to $40 \%$ at $210 \mathrm{~min}$ tos. Also, the yields of $\mathrm{H}_{2}, \mathrm{H}_{2} \mathrm{O}$ and $\mathrm{CH}_{4}$ raise, even if the latter two remain-very low. The $\mathrm{O}$ release from the solid exhibits a very rapid growth, which can be related to the increase of $\mathrm{CO}_{2}$ yield.

The main reactions occurring during Zone III are:

$$
\mathrm{CH}_{3} \mathrm{OH}+\mathrm{Me}^{\mathrm{n}+} \mathrm{O} \rightarrow \mathrm{CO}_{2}+2 \mathrm{H}_{2}+\mathrm{Me}^{(\mathrm{n}-2)+}
$$


(this explains the increase of $\mathrm{CO}_{2}$ and $\mathrm{H}_{2}$ yield, as well as the raise of $\mathrm{O}$ release from the solid), and

$$
2 \mathrm{CO} \rightarrow \mathrm{CO}_{2}+\mathrm{C}
$$

(this explains the increase of $\mathrm{CO}_{2}$ and $\mathrm{C}$ and the simultaneous decrease of $\mathrm{CO}$ ).

The formation of $\mathrm{H}_{2} \mathrm{O}$ may occur, instead, either via Reverse Water-Gas-Shift (RWGS):

$$
\mathrm{CO}_{2}+\mathrm{H}_{2} \rightarrow \mathrm{CO}+\mathrm{H}_{2} \mathrm{O}
$$

(this could be caused by the high concentration of $\mathrm{CO}_{2}$ and $\mathrm{H}_{2}$ ), or, less likely, via total oxidation of methanol:

$$
\mathrm{CH}_{3} \mathrm{OH}+2 \mathrm{Me}^{\mathrm{n}+} \mathrm{O} \rightarrow \mathrm{CO}_{2}+2 \mathrm{H}_{2} \mathrm{O}+2 \mathrm{Me}^{(\mathrm{n}-2)+}
$$

For what concerns the oxygenated compounds, the formic acid yield continuously increases, reaching the value of $0.40 \%$ after $210 \mathrm{~min}$ tos, whereas the methylformate yield passes from $0.01 \%$ to $0.03 \%$.

During the period 210-380 min tos (Zone IV), methanol conversion decreases, and, at the same time, also the continuous decrease of coke and $\mathrm{CO}_{2}$ yields is observed, together with the simultaneous formation of CO. Still, both the $\mathrm{H}_{2}$ yield and the amount of $\mathrm{O}$ released decrease in Zone IV. The observed phenomenon is probably due to a lower contribution of reaction 1 (leading to $\mathrm{CO}_{2}$ and $\mathrm{H}_{2}$ formation) and reaction 5 (leading to coke and $\mathrm{CO}_{2}$ formation). The spinel reduction rate progressively decreases, approaching the limit value corresponding to the total spinel reduction. Finally, it seems that the only reaction which contributes to methanol conversion is reaction 3 :

$$
\mathrm{CH}_{3} \mathrm{OH} \rightarrow \mathrm{CO}+2 \mathrm{H}_{2}
$$

as highlighted by $\mathrm{CO}$ and $\mathrm{H}_{2}$ yields, which seem to reach similar values.

Concerning oxygenated compounds, methylformate yield decreases continuously from $0.03 \%$ to $0 \%$ at 330 min tos, whereas formic acid yield reaches the maximum value $(0.55 \%$ at 270 min tos $)$, and then decreases down to $0.25 \%$ at $380 \mathrm{~min}$ tos.

When the reaction with methanol is carried out at $420^{\circ} \mathrm{C}$ (these results are not reported here for the sake of brevity), all the phenomena occur much faster, and the different Zones are hardly 
distinguished. Zone I is missed, and the total sample reduction is reached after 70 min only. The CO yield does not show the oscillating trend observed at $300^{\circ} \mathrm{C}$, but, on the contrary, displays a continuous increase; moreover, the maximum $\mathrm{CO}_{2}$ yield (which coincides with the maximum $\mathrm{H}_{2} \mathrm{O}$ yield) can be observed after 11 minutes only. Still, another important difference concerns the trend of coke formation: coke yield increases continuously in the 0-70 min range (reaching a value of $40 \%$ ), and then keeps constant for reaction times longer than $70 \mathrm{~min}$.

Figure 7 shows the experimental results obtained with CF750. In general, the catalytic behavior is analogous to that of CF450; however, some important differences are worth noting:

Zone I is much shorter; after $4 \mathrm{~min}$, in fact, $\mathrm{O}$ release from the solid starts to raise. Also in this case, in Zone I the main products are $\mathrm{CO}_{2}$ and $\mathrm{H}_{2}$.

Zones II ends within 90-100 min tos (the same time range of the CF450 sample), whereas Zone III concludes after 140 min tos. At this tos the following steps are reached: (i) the maximum degree of $\mathrm{O}$ release, (ii) the maximum methanol conversion, (iii) the higher $\mathrm{CO}_{2}$ and coke yields and (iv) the lower CO yield.

Zone IV leads to the maximum value of $\mathrm{CO}$ yield (recorded at $260 \mathrm{~min}$ tos), after which a continuous decrease of methanol conversion, as well as $\mathrm{CO}$ and $\mathrm{H}_{2}$ yields, can be observed. Still, coke formation is definitely limited.

Throughout the range (0-380 $\mathrm{min}$ tos), it has not been possible to observe the formation of either dimethoxymethane, formic acid or formaldehyde. Methylformate is the only product formed between 110 and $220 \mathrm{~min}$ tos with the $0.02 \%$ of yield.

The maximum oxide reduction degree is, in this case, only $82 \%$ (Figure 8 ).

Overall, it is possible to state that, in the more crystalline CF750 sample, a lower concentration of highly reactive surface sites are present (this is in good agreement with the features of all samples reported previously, [57]). By considering the overall extent of reduction evaluated for the two samples in Zone I (0.17\% after $4 \mathrm{~min}$ tos for CF750, 3.5\% after $22 \mathrm{~min}$ tos for CF450), 
it comes out that this discrepancy is not ascribable only to the different values of surface area, but specifically to the distinct surface features, that is, the different spinel crystallinity of the two samples. In other words, these data confirm the presence of highly reactive (reducible) surface species in CF450, which on the contrary, are less exposed in the case of CF750. These reducible species could be the surface octahedral $\left(\mathrm{Co}^{2+} / \mathrm{Fe}^{3+}\right)$ sites that are present in larger amount at the surface of the CF450 sample and are not exposed anymore at the surface of CF750 sample, as previously demonstrated by the FTIR analysis.

In order to gain further information regarding the well distinct behaviors of the two samples, especially for what concerns the starting reactivity (Zone I), a study of the surface features has been carried out by means of FTIR spectroscopy, contacting the samples with methanol.

\section{Effect of thermal annealing on surface characteristics: the interaction with methanol}

The study of methanol adsorption has been carried out to gain information about the materials of interest behaviour during the starting period of the reaction. After methanol contact at beam temperature (BT, i.e. the temperature of the sample in the IR beam) with both systems [curves (1) in section (a) and (b) of Fig. 9], a complex band can be observed in the $1550-1300 \mathrm{~cm}^{-1}$ range, produced by methanol interaction with surface sites. As reference, it can be considered methanol adsorption on Aerosil 200 (commercial pyrogenic silica by Evonik) activated at $150^{\circ} \mathrm{C}$ (dotted line in section (a)). Pure silica is conveniently used for this purpose because of its scarce activity and null reactivity: it can interact with probe molecules only through surface $\mathrm{OH}$-groups, giving rise to weak H-bonding interactions [62].

For what concerns the $\mathrm{CF} 450$ catalyst, increasing the temperature up to $150^{\circ} \mathrm{C}$ in methanol atmosphere, different signals appear in the spectrum [curve (2) in section (a)]. They can be confidently ascribed to adsorbed formate ions, that give rise to a typical band triplet due to the following modes: asymmetric COO stretching ( $v_{\text {OCOas }}$; strong band at $\sim 1570 \mathrm{~cm}^{-1}$ ), $\mathrm{CH}$ deformation 
$\left(\delta_{\mathrm{CH}}\right.$; weak sharp signal at $\sim 1375 \mathrm{~cm}^{-1}$ ) and symmetric COO stretching ( $v_{\mathrm{OCO}}$; medium band at $\sim 1355 \mathrm{~cm}^{-1}$ ) [63]. Also, the presence of a relevant amount of adsorbed methyl formate (the dimer of formaldehyde) is evidenced by bands at $\sim 1600$ and $\sim 1460 \mathrm{~cm}^{-1}$, ascribed to the $\mathrm{C}=\mathrm{O}$ stretching and asymmetric/symmetric $\mathrm{CH}_{3}$ bending, respectively [64,65]. Comparison between spectra (1) and (2) of section (a) indicates that minor amounts of the formate species form already at BT. Methanol at relatively low temperatures dehydrogenates to formaldehyde, that readily reacts to generate surface formate species; this process requires the reduction of the employed material to take place. The generation of formate ions confirms the capacity of methanol to reduce the material at relatively low temperature.

By heating up the sample above $200^{\circ} \mathrm{C}$ in methanol atmosphere, it is possible to observe (not shown in the figure) the total loss of transparency of the solid sample to infrared radiation. This radical change of optical features can be attributed to the further reduction of the system. In fact, the reduction process may not be only a surface phenomenon, but can involve the migration of $\mathrm{O}^{2-}$ ions from the bulk towards the surface, generating drastic mutations in the electronic behavior of the material.

Going back to methanol adsorption on the CF750 catalyst, the differential spectral pattern reported in section (b) of Fig. 9 shows that the signals of formate species are weak and ill-defined, even after the increase of the temperature up to $250^{\circ} \mathrm{C}$ in methanol atmosphere, indicating a less reactive system. In this case, the total loss of transparency of the solid to infrared radiation (indicating a deep reduction of the system) is observed upon heating the sample above $250^{\circ} \mathrm{C}$ in methanol atmosphere. This fact highlights that the reduction of this system needs higher temperatures and longer contact times with methanol than in the case of the CF450 catalyst. In other words, the migration phenomenon of $\mathrm{O}^{2-}$ ions from the bulk towards the surface is slower for the more crystalline oxide. These last considerations are in good agreement with the catalytic data, in 
which the maximum spinel reduction degree is close to $100 \%$ for the CF450, whereas it is only $82 \%$ for the CF750.

The IR study of methanol adsorption allows the statement that this molecule is a good reducing agent for $\mathrm{CoFe}_{2} \mathrm{O}_{4}$ at relatively low temperatures; still, the $\mathrm{CF} 750$ system requires higher temperatures to reach the same reduction degree. Moreover, the information provided are in line with experimental results obtained during the initial reactivity tests of samples with methanol (starting period of Zone I, when the solid is still oxidized): the highly reactive surface species present in the CF450 spinel (i.e, the octahedral $\left(\mathrm{Co}^{2+} / \mathrm{Fe}^{3+}\right)$ sites), are exposed in much less amount in CF750 sample.

\section{Bulk characteristics of used (reduced and then reoxidized) catalysts}

Catalytic and characterization results reported so far highlight that the initial reactivity of CF450 and CF750 spinels is quite different, because of the presence of highly reactive sites in the former oxide, which are only a lower fraction in the case of CF750. These sites are readily consumed during the very first minutes reaction time in methanol anaerobic oxidation carried out at $300^{\circ} \mathrm{C}$ (Zone I), and the reduction degree achieved during Zone I is greatly different for the two samples.

As the use of the spinel as a catalyst for methanol transformation into $\mathrm{H}_{2}$ would necessarily imply a regeneration step of the reduced solid, it is very important to know if both surface and bulk features of the solids remain the same after a reoxidation step. For this reason, the effects of the reoxidation with steam were studied on reduced CF450 and CF750 samples. Moreover, this step provides an additional source for $\mathrm{H}_{2}$, in the so-called Steam-Iron process, derived from the Thermochemical Reforming approach [66-70].

Table 1 reports the main morphological features of both used (reduced and then reoxidized) CF450 and CF750 samples, after partial and complete reduction; the reduction step was carried out 
at two different temperatures, $300^{\circ} \mathrm{C}$ and $420^{\circ} \mathrm{C}$. For example, in the case of the partially reduced $\mathrm{CF} 450$, the reduction at $300^{\circ} \mathrm{C}$ was stopped after 30 minutes (which roughly corresponds to the end of Zone I, with a degree of spinel reduction corresponding to $\sim 4.5 \%$ ), whereas the completely reduced (and strongly coked) sample was obtained by downloading the solid after 300 min (Zone IV). The data clearly indicate that the redox cycle (reduction with methanol + oxidation with steam) does not produce any relevant modification in the CF750 sample, whereas, on the contrary, it deeply affects the characteristics of the CF450. The reoxidized CF450 in fact exhibits a remarkable increase of the crystallinity and a parallel decrease of the surface area. In other words, after just one complete redox cycle the CF450 becomes very similar to the CF750. It is important to highlight that this phenomenon cannot be due to any high-temperature treatment, as both the reduction with methanol (an endothermal process) and the oxidation with steam (a mildly exothermal process) have been carried out at temperatures not higher than $420^{\circ} \mathrm{C}$.

Figure 10 shows the HR-TEM pictures of samples after contact with methanol at $420^{\circ} \mathrm{C}$ and reoxidation with steam; the images reveal an increase of crystallite size with respect to the fresh samples, ranging now from $\sim 15$ to $\sim 35 \mathrm{~nm}$ for CF450 and from $\sim 30$ to $\sim 40 \mathrm{~nm}$ for CF750. Moreover, particles contours appear well-outlined and definitely more roundish if compared with those of fresh samples. All this confirms that CF450 undergoes irreversible morphological changes, whereas CF750 undergoes minimal morphological modifications.

Figure 11, showing XRD patterns of samples after reduction at $420^{\circ} \mathrm{C}$ and reoxidation with steam, provides additional information. It is confirmed that the crystallinity of CF450 and CF750, which was very different for the freshly calcined samples, becomes very similar after the redox cycle. Moreover, both samples show some weak reflections ascribable to metallic $\mathrm{Co} / \mathrm{Fe}$ alloy and metallic Co, which are especially evident in the case of the used CF450.

In the IR spectrum of used CF450 (first completely reduced by interaction with methanol at $420^{\circ} \mathrm{C}$ for $180 \mathrm{~min}$, and then reoxidized with steam at $420^{\circ} \mathrm{C}$ ), the component at $\sim 620 \mathrm{~cm}^{-1}$ is no 
longer evident (see the dotted-line curve in Fig. 3, top); this high- $v$ signal can be ascribed to the surface fraction of the $(\mathrm{Fe}-\mathrm{O})_{\mathrm{Th}}$ vibrational modes which considerably decrease as a consequence of the drastic decrease of surface area produced after the reduction/oxidation cycle. The band ascribable to bulk $(\mathrm{Fe}-\mathrm{O})_{\text {Th }}$ vibrations shifts from $\sim 587 \mathrm{~cm}^{-1}$ (see the solid line trace of the calcined sample in section (a) of Fig. 3 top) to $\sim 578 \mathrm{~cm}^{-1}$, due to the changed (increased) particles size caused by sintering phenomena. The same behaviour was previously observed upon increasing the calcination temperature from $450^{\circ} \mathrm{C}(\mathrm{CF} 450)$ to $750^{\circ} \mathrm{C}(\mathrm{CF} 750)$.

In the case of CF750, as the morphological changes of used sample are less important than those of used CF450, the position of the band at $\sim 580 \mathrm{~cm}^{-1}$ remains virtually unchanged before and after the reduction/oxidation cycle [see the dotted-line curve in section (b) of Fig.3 top], even if also in this case the use of the material as a reagent/catalyst reduces (to a fairly limited extent) the high- $v$ component of the overall $(\mathrm{Fe}-\mathrm{O})_{\mathrm{Th}}$ vibrational band.

For what concerns the computer resolved spectra of used samples in the $800-500 \mathrm{~cm}^{-1}$ spectral range (Fig. 3, bottom, spectral sets II), it is possible to observe that:

i. the intensity of the bulk $(\mathrm{Fe}-\mathrm{O})_{\mathrm{Th}}$ component $\left(\mathrm{B}_{\mathrm{Th}}\right)$ remains unchanged in both fresh and used samples. This feature is actually the main basis of the band assignment;

ii. the surface component $\left(\mathrm{S}_{\mathrm{Th}}\right)$, on the contrary, decreases of $\sim 30 \%$ after the employment in the redox cycle;

iii. the $\mathrm{S}_{(\mathrm{Th})} / \mathrm{B}_{(\mathrm{Th})}$ integrated intensity ratio decreases for both samples after their employment in the redox cycle (from 0,85 to 0,59 for $\mathrm{CF} 450$ and from 0,6 to 0,38 for CF750). This confirms that the surface area decreasing, produced during the redox cycle, leads to the loss of an appreciable fraction of surface tetrahedral $\left(\mathrm{Fe}^{3+}\right)$ sites, regardless of the starting SSA value.

For what concerns the spectra of used samples collected in the far-IR region (dotted lines in section (a) and (b) of Fig. 4, top), it is possible to observe that the component at $\sim 415 \mathrm{~cm}^{-1}$ is no 
longer evident in the spectrum of the CF450 material employed in the redox cycle (see the dottedline curve in section (a)). As in the case of the $(\mathrm{Fe}-\mathrm{O})_{\mathrm{Th}}$ modes, the high- $\mathrm{v}$ signal can be ascribed to the surface fraction $\left(\mathrm{S}_{\mathrm{Oh}}\right)$ of both $(\mathrm{Fe}-\mathrm{O})_{\mathrm{Oh}}$ and $(\mathrm{Co}-\mathrm{O})_{\mathrm{Oh}}$ vibrations, which noticeably decreases after the employment in the reaction, due to the drastic decrease of surface area. In the case of used CF750, as the morphological changes are less important than those shown by used CF450, the shape of the octahedral complexes band envelope remains virtually unchanged before and after the reduction/oxidation cycle [see the dotted-line curve in section (b), with respect to the solid-line one].

All the previous considerations can be confirmed by observing the band-resolved spectra reported in Fig. 4 (bottom, spectral sets II). The following can be observed:

i. the surface component $\left(\mathrm{S}_{\mathrm{Oh}}\right)$ decreases of $\sim 40 \%$ after the use in the reaction only in the case of the CF450 sample, whereas for the CF750, no changes of this band are observed; for CF450, the integrated absorbance of the $S_{\mathrm{Oh}}$ component passes from 16 to $6 \mathrm{~cm}^{-1}$, whereas for CF750 the integrated absorbance is $6 \mathrm{~cm}^{-1}$ in both calcined and used samples.

ii. the bulk components $\left(\mathrm{B}_{\mathrm{Fe}(\mathrm{Oh})}\right.$ and $\left.\mathrm{B}_{\mathrm{Co}(\mathrm{Oh})}\right)$ seem to increase slightly on passing from fresh to used CF450, whereas they remain virtually unchanged for CF750.

Taking into account all previous considerations about the used samples, it is possible to state the following:

i. both materials lose a fraction of surface $\mathrm{Fe}^{3+}$ tetrahedral sites during the redox cycle. In any case, the amount of this type of surface sites is higher on CF450, both fresh calcined and used materials;

ii. the fraction of surface $\mathrm{Fe}^{3+} / \mathrm{Co}^{2+}$ octahedral complexes remains unchanged in the case of CF750;

iii. the CF450 material shows a consistent loss of surface $\mathrm{Fe}^{3+} / \mathrm{Co}^{2+}$ octahedral sites during the employment in the redox cycle, conforming with both calcined and used CF750 samples. 
Thus, after TEM and XRD analyses, also FTIR spectroscopy confirms that the two cobalt ferrites CF450 and CF750, originally morphologically quite different from one another, become very similar after just one redox cycle.

\section{Surface characteristics of used (reduced and then oxidized) samples}

During the oxidation step with water, the materials should recover part or all of the transparency to infrared radiation previously lost as a consequence of the complete or almost complete reduction. Actually, this does not happen, probably because the reoxidation with water is slow. In order to recover transparency to infrared radiation, it was found to be necessary to carry out an activation/oxidation in the presence of oxygen, as follows [see curves (2) in Fig. 12]: (i) 20 minutes of evacuation at $350^{\circ} \mathrm{C}$, (ii) 20 minutes contact with 60 Torr of $\mathrm{O}_{2}$ at $350^{\circ} \mathrm{C}$, and (iii) 20 minutes of evacuation, decreasing gradually the temperature down to RT. In both cases, after the thermal treatment in $\mathrm{O}_{2}$, it was possible to observe the presence of a band at $\sim 2343 \mathrm{~cm}^{-1}$, ascribable to linearly adsorbed $\mathrm{CO}_{2}$ [71] that derives from the oxidative thermal decomposition of carbonaceous contaminant species. The band of linearly held $\mathrm{CO}_{2}$ remained unchanged also after prolonged evacuation at $\mathrm{BT}$, suggesting that $\mathrm{CO}_{2}$ became trapped inside the solid during the redox process. This fact is consistent with the drastic decrease in surface area of these materials, causing by sintering after just one reduction/oxidation cycle.

For what concerns the $1600-1200 \mathrm{~cm}^{-1}$ spectral range, some differences are evident for the two catalysts.

CF450 shows an abundant increase of the signals ascribable to carbonate-like species [71]. In this case, $\mathrm{CO}_{2}$ and, consequently, carbonates derive from surface carbonaceous contaminant species that during the contact with oxygen at $350^{\circ} \mathrm{C}$ decompose to carbon dioxide;

For CF750, the increasing of carbonate-like complexes is barely visible, whereas two signals at 1560 and $1450 \mathrm{~cm}^{-1}$, generated by formate species, clearly appear in the spectrum $[64,65]$. These 
species, once formed during the reduction step with methanol, remain irreversibly adsorbed at the surface of the sample.

As demonstrated by the IR spectra collected after the re-oxidation with oxygen, the surface of the two catalysts appears irreversibly modified. This result allows to assert that these materials irreversibly lose some of their starting features after only one reduction/oxidation cycle, and recover them no more.

\section{Conclusions}

Methanol anaerobic oxidation over $\mathrm{CoFe}_{2} \mathrm{O}_{4}$ inverse spinel has been studied in this work. A correlation between physico-chemical properties and catalytic performances of the material has been pursued: in particular, it has been evidenced that bulk and surface features of the spinel oxide change after contacting the metal oxide first with methanol and then with steam.

In order to evaluate the effect of different morphological features on methanol reaction, the material has been calcined at two different temperatures $\left(450^{\circ} \mathrm{C}\right.$ and $\left.750^{\circ} \mathrm{C}\right)$, so as to control the growth of the crystallites.

The study of both surface and bulk properties has been carried out by means of different experimental techniques. FTIR analysis of the typical spectral features of the spinel phase demonstrates that the thermal treatment is responsible for the different type of exposed surface sites: in particular, surface octahedral $\left(\mathrm{Co}^{2+} / \mathrm{Fe}^{3+}\right)$ sites are present in a larger amount on the $\mathrm{CF} 450$ if compared with the CF750. As the above mentioned species are the most reactive (i.e., reducible), the two samples exhibit a different behavior, as demonstrated by both catalytic tests and FTIR study of methanol adsorption. The most important differences in the reactivity concern the early stage of the reaction (Zone I), in which the highly reactive sites are readily consumed, and the last stages (Zone IV), in which the final reduction degree achieved by the two materials is different ( $\sim 100 \%$ for CF450, and $\sim 82 \%$ for CF750). 
After the evaluation of the main differences between the fresh calcined samples, both surface and bulk features of the reoxidized solids have been studied. The thorough knowledge of these properties is very important, as the use of the spinel as catalyst for methanol transformation into $\mathrm{H}_{2}$ necessarily implies a regeneration step, in order to recover the oxidative capacity of the solid. All the characterization techniques employed in this work (XRD, TEM and FTIR spectroscopy) reveal that the two cobalt ferrites (CF450 and CF750), originally morphologically quite different from one another, become very similar after just one redox cycle. Still, FTIR spectroscopy clearly shows that both used materials irreversibly modify their surface properties after the reduction/oxidation with methanol and steam, exhibiting a very different spectral pattern if compared with the fresh solids.

All these results highlight that the preliminary thorough comprehension of both morphologic and surface chemical features of these materials (combining different characterization techniques) is an essential step in order to choose the best catalytic material and, consequently, to optimize the reaction operative parameters.

\section{Acknowledgements}

MIUR (Ministero dell'Università e della Ricerca) is acknowledged for the $\mathrm{PhD}$ grant to Stefano Cocchi (Progetto Giovani).

\section{References}

1. Zinoviev S., Müller-Langer F., Das P., Bertero N., Fornasiero P., Kaltschmitt M., Centi G., Miertus S. ChemSusChem 2010, 3, 1106 - 1133.

2. Olah G.A. Angew. Chem. Int. Ed. 2005, 44, 2636-2639.

3. Palo D.R., Dagle R.A., Holladay J.D. Chem. Rev. 2007, 107, 3992-4021.

4. Sá S., Silva H., Brandão L., Sousa J.M, Mendes A. Appl. Catal. B 2010, 99, 43-57.

5. Holladay J.D., Hu J., King D.L., Wang Y. Catal. Today 2009, 139, 244-260. 
6. Navarro R.M., Peña M.A., Fierro J.L.G. Chem. Rev. 2007, 107, 3952-3991.

7. Hohn K.L., Lin Y.-C. ChemSusChem 2009, 2, 927-940.

8. Zum Mallen M.P., Schmidt L.D. J. Catal. 1996, 161, 230-246.

9. Agrell J., Boutonnet M., Fierro J.L.G. Appl. Catal. A 2003, 253, 213-223.

10. Rennard D.C., Kruger J.S., Schmidt L.D. ChemSusChem 2009, 2, 89-98.

11. Lin Y.-C, Hohn K.L., Stagg-Williams S.M. Appl. Catal. A 2007, 327, 164-172.

12. Velu S., Suzuki K., Okazaki M., Kapoor M.P., Osaki T., Ohashi F. J. Catal. 2000, 194, 373-384.

13. Papavasiliou J., Avgouropoulos G., Ioannides T. J. Catal. 2007, 251, 7-20.

14. Navarro R.M., Peña M.A., Fierro J.L.G. J. Catal. 2002, 212, 112-118.

15. Choi Y., Stenger H.G. Appl. Catal. B 2002, 38, 259-269.

16. Kapoor M.P., Raj A., Matsumura Y. Microp. Mesop. Mater. 2001, 44-45, 565-572.

17. Fisher I.A., Bell A.T. J. Catal. 1999, 184, 357-376.

18. Matsumura I., Tanaka K., Tode N., Yazawa T., Haruta M. J. Mol. Catal. A: Chem. 2000, 152, $157-165$.

19. Boccuzzi F., Chiorino A., Manzoli M. J. Power Sources 2003, 118, 304-310.

20. Jackson S.D., Anderson D.S., Kelly G.J., Lear T., Lennon D., Watson S.R. Top. Catal. 2003, 22, $173-182$.

21. Minchev C., Koehn R., Tsoncheva T., Dimitrov M., Mitov I., Paneva D., Huwe H., Froeba M. Stud. Surf. Sci. Catal. 2002, 142B, 1245-1252.

22. Koehn R., Paneva D., Dimitrov M., Tsoncheva T., Mitov I., Minchev C., Froeba M. Microp. Mesop. Mater. 2003, 63, 125-137.

23. Paneva D., Tsoncheva T., Manova E., Mitov I., Ruskov T. Appl. Catal. A 2004, 267, 67-75.

24. Manova E., Tsoncheva T., Estournès Cl., Paneva D., Tenchev K., Mitov I., Petrov L. Appl. Catal. A 2006, 300, 170-180.

25. Zafeiratos S., Dintzer T., Teschner D., Blume R., Hävecker M., Knop-Gericke A., Schlögl R. J. Catal. 2010, 269, 309-317.

26. Llorca J., de la Piscina P.R., Dalmon J.-A., Sales J., Homs N. Appl. Catal. B 2003, 43, 355-369.

27. Ni M., Leung D.Y.C., Leung M.K.H. Int. J. Hydrogen Energy 2007, 32, 3238 -3247.

28. Chen W.S., Lee M.D., Lee J.F. Appl. Catal. 1992, 83, 201-211.

29. Xiong Ch-R., Chen Q.L.,Lu W.-R., Gao H.-X., Lu W.-K., Gao Z. Catal. Lett. 2000, 69, 231-236.

30. Sreekumar K., Mathew T., Rajgopal R., Vetrivel R., Rao B.S. Catal. Lett. 2000, 65, 99-105. 
31. Lazar K., Mathew T., Koppany Z., Megyeri J., Samuel V., Mirajkar S.P., Rao B.S., Guczi L. Phys. Chem. Chem. Phys. 2002, 4, 3530-3536.

32. Grabowska H., Kaczmarczyk W., Wrzyszcz J. Appl. Catal. 1989, 47, 351-355.

33. Ghorpade S., Darshane V.S., Dixit S.G. Appl. Catal. A 1998, 166, 135-142.

34. Oh S.H., Sinkevitch R.M. J. Catal. 1993, 142, 254-262.

35. Mathew T., Shylesh S., Reddy S.N., Sebastian C.P., Date S.K., Rao B.S., Kulkarni S.D., Catal. Lett. 2004, 93, 155-163.

36. Sreekumar K., Sugunan S. J. Mol. Catal. A 2002, 185, 259-268.

37. Ramankutty C.G., Sugunan S. Appl. Catal. A 2001, 218, 39-51.

38. Tihay F., Roger A.C., Pourroy G., Kiennemann A. Energy Fuels 2002, 16, 1271-1276.

39. Mathew T., Malwadkar S., Pai S., Sharanappa N., Sebastian C.P., Satyanarayana C.V.V., Bokade V.V. Catal. Lett. 2003, 91, 217-224.

40. Mathew T., Shiju N.R., Sreekumar K., Rao B.S., Gopinath C.S. J. Catal. 2002, 210, 405-417.

41. Mathew T., Vijayaraj M., Pai S., Pope B.T., Hedge S.G., Rao B.S., Gopinath C.S. J.Catal. 2004, $227,175-185$.

42. Mathew T., Shylesh S., Devassy B.M., Vijayaraj M., SatyanarayanC.V.V., Rao B.S., Gopinath C.S. Appl. Catal. A 2004, 273, 35-45.

43. Mathew T., Rao B.S., Gopinath C.S., J. Catal. 2004, 222, 107-116.

44. Mathew T., Shiju N.R., Tope B.B., Hegde S.G., Rao B.S., Gopinath C.S. Phys. Chem. Chem. Phys. 2002, 4, 4260-4267.

45. Ferreira T.A.S., Waerenborgh J.C., Mendoca M.H.R.M., Nunes M.R., Costa F.M. Solid State Sci. 2003, 5, 383-392.

46. Jacobs J.-P., Maltha A., Reintjes J.G.H., Drimal J., Ponec V., Brongersma H.H. J. Catal. 1994, 147, 294-300.

47. Ziolkowski J., Barbaux Y. J. Mol. Catal. 1991, 67, 199-215. 
48. De Guide M.R., O’Handley R.C., Kalonji G. J. Appl. Phys. 1989, 65, 3167-3172.

49. Li S., John V.T., O’Connor C., Harris V., Carpenter E. J. Appl. Phys. 2000, 87, 6223-6225.

50. Khedr M.H., Omar A.A., Abdel-Moaty S.A. Coll. Surf. A 2006, 281, 8-14.

51. Manova E., Kunev B., Paneva D., Mitov I., Petrov L., Estournès C., D’Orléans C., Rehspringer J.-L., Kurmoo M. Chem. Mater. 2004, 16, 5689-5696.

52. Qu Y., Yang H., Yang N., Fan Y., Zhu H., Zou G. Mater. Lett. 2006, 60, 3548-3552.

53. Mathew D.S., Juang R.S. Chem. Eng. J. 2007, 129, 51-65.

54. Sreekumar K., Sugunan S Appl. Catal. A 2002, 230, 245-251.

55. Manova E., Tsoncheva T., Paneva D., Mitov I., Tenchev K., Petrov L. Appl. Catal. A 2004, 277, 119-127.

56. Pillai V., Shah D.O. J. Magnet. Magn. Mater. 1996, 163, 243-248.

57. Ballarini N., Cavani F., Passeri S., Pesaresi L., Lee A.F., Wilson K. Appl. Catal. A 2009, 366, $184-192$.

58. Meng Y., Chen D., Jiao X. Eur. J. Inorg. Chem. 2008, 4019-4023.

59. Waldron R.D. Phys. Rev. 1955, 99, 1727-1735.

60. Josyula O.S., Sobhanadri J. Phys. Status Solidi A 1981, 65, 479-483.

61. Gabal M.A., Ata-Allah S.S. Mat. Chem. Phys. 2004, 85, 104-112.

62. Morterra C., Magnacca G., Bolis V. Catal. Today 2001, 70, 43-58.

63. Busca G.. Catal. Today 1996, 27, 457-496.

64. Colthup N.B., Daly L.H., Wiberley S.E. Introduction to Infrared and Raman Spectroscopy, 2nd ed.; Academic Press: New York, 1975.

65. Popova J.Y., Andrushkevich T.V., Chesalov Y.A., Stonayov E.S. Kinet. Catal. 2000, 41, 805810.

66. Kodama T., Gokon N. Chem. Rev. 2007, 107, 4048-4077.

67. Bohmer M., Langnickel U., Sanchez M. Solar Energy Mater. 1991, 24, 441-448. 
68. Otsuka K., Yamada C., Kaburagi T., Takenaka S. Int. J. Hydrogen Energy 2003, 28, 335 - 34.

69. Heidebrecht P., Sundmacher K. Chem. Eng. Sci. 2009, 64, 5057-5065.

70. Lorente E., Peña J.A., Herguido J. Int. J. Hydrogen Energy 2008, 33, 615-626.

71. Busca G., Lorenzelli V. Mater. Chem. 1982, 7, 89-126. 
Table 1. Main features of fresh calcined and used ${ }^{\mathrm{a}}$ (in different conditions) samples.

\begin{tabular}{|l|l|c|c|}
\hline Sample & Performed treatment & \multicolumn{2}{|c|}{ Characteristics after the treatment } \\
\hline & & Surface area, $\mathrm{m}^{2} / \mathrm{g}$ & Crystalite size, $\mathrm{nm}$ \\
\hline CF450 & Calcined (no reduction) & $70 \pm 14^{\mathrm{b}}$ & $15 \pm 2^{\mathrm{b}}$ \\
CF450 & T $300^{\circ} \mathrm{C}, 30 \mathrm{~min}$ & 30 & $\mathrm{nd}$ \\
CF450 & T $300^{\circ} \mathrm{C}, 300 \mathrm{~min}$ & 35 & $\mathrm{nd}$ \\
CF450 & T $420^{\circ} \mathrm{C}, 30$ min & 9 & $\mathrm{nd}$ \\
CF450 & T $420^{\circ} \mathrm{C}, 30$ min* & 23 & 32 \\
CF450 & T $420^{\circ} \mathrm{C}, 180$ min* & 10 & 54 \\
\hline CF750 & Calcined (no reduction) & $9 \pm 2^{\mathrm{b}}$ & $41 \pm 9^{\mathrm{b}}$ \\
CF750 & T $300^{\circ} \mathrm{C}, 30$ min & 10 & $\mathrm{nd}$ \\
CF750 & T $300^{\circ} \mathrm{C}, 300$ min & nd & nd \\
CF750 & T $420^{\circ} \mathrm{C}, 30$ min & 10 & nd \\
CF750 & T $420^{\circ} \mathrm{C}, 30$ min* & 10 & 33 \\
CF750 & T $420^{\circ} \mathrm{C}, 180$ min* & 6 & 55 \\
\hline
\end{tabular}

"All "used" samples were first reduced in methanol and then reoxidized. Reoxidation was carried out in all cases at $420^{\circ} \mathrm{C}$ for $1 \mathrm{~h}$, using a $29 \%$ steam in $\mathrm{N}_{2}$ flow, with contact time $0.25 \mathrm{~s}$ (with the exception of experiments denoted with an asterisk, for which the contact time was $1 \mathrm{~s}$ ). nd = not determined.

${ }^{b}$ The error was calculated by repeating measurements on several samples. 
FIGURE 1

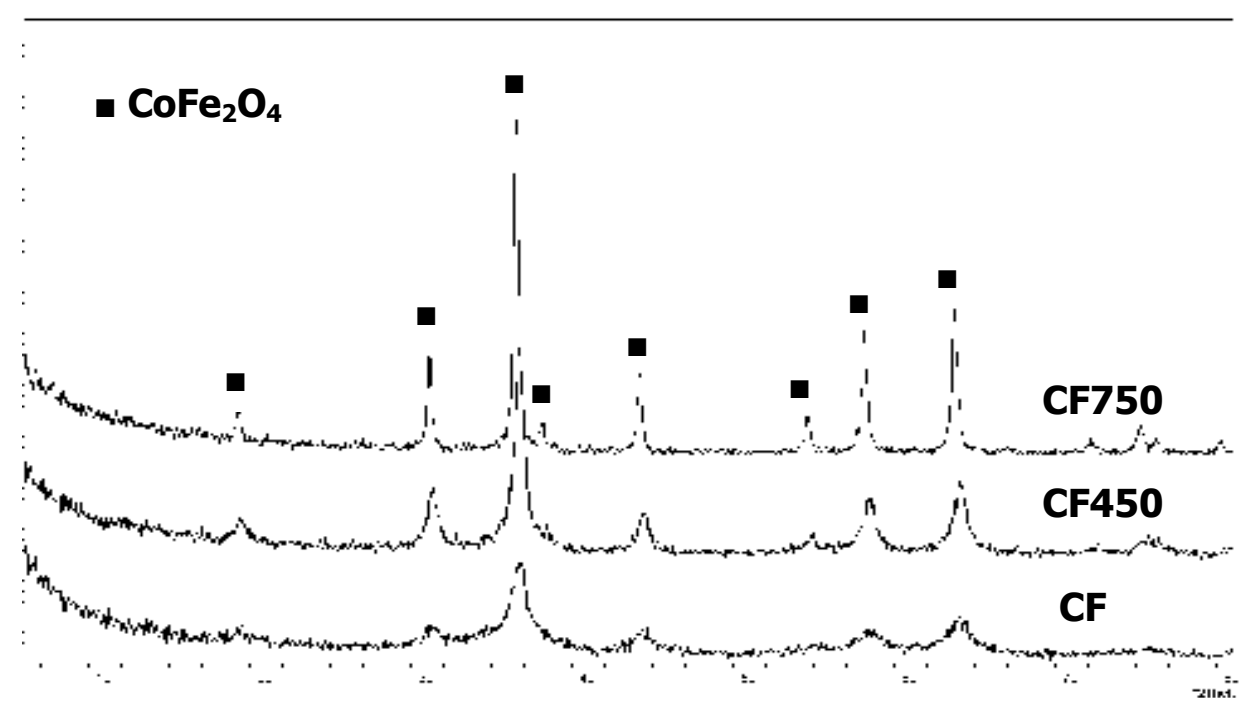

Figure 1. XRD patterns of the freshly precipitated and dried $\left(120^{\circ} \mathrm{C}\right)$ sample $(\mathrm{CF})$, and of calcined samples (CF450 and CF750). 
FIGURE 2
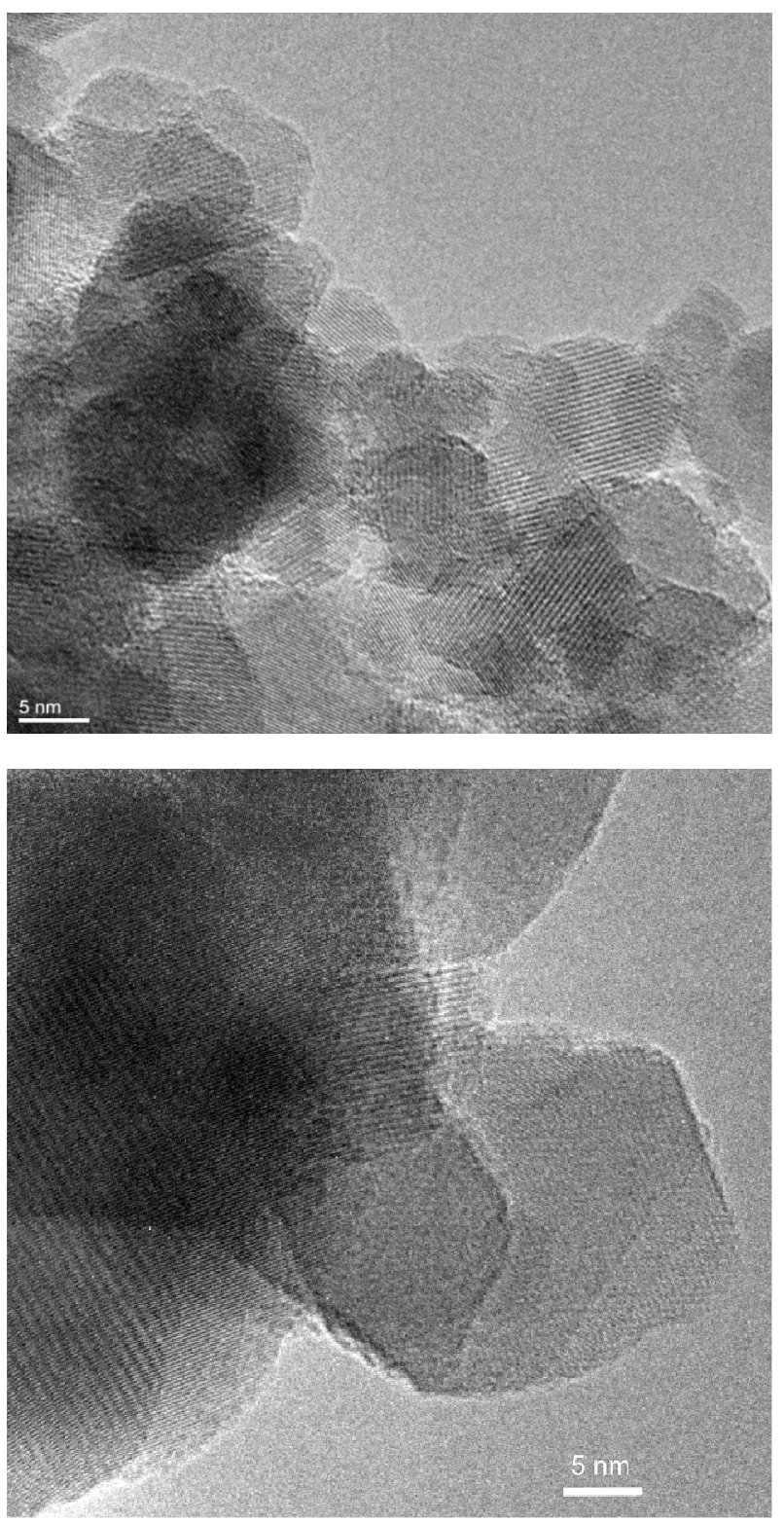

Figure 2. HR-TEM images of CF450 (top) and CF750 (bottom). The images were taken on fresh samples CF450 (surface area $70 \mathrm{~m}^{2} / \mathrm{g}$, crystallite size $13 \mathrm{~nm}$ ) and CF750 (surface area $10 \mathrm{~m}^{2} / \mathrm{g}$, crystallite size $32 \mathrm{~nm})$. 
FIGURE 3
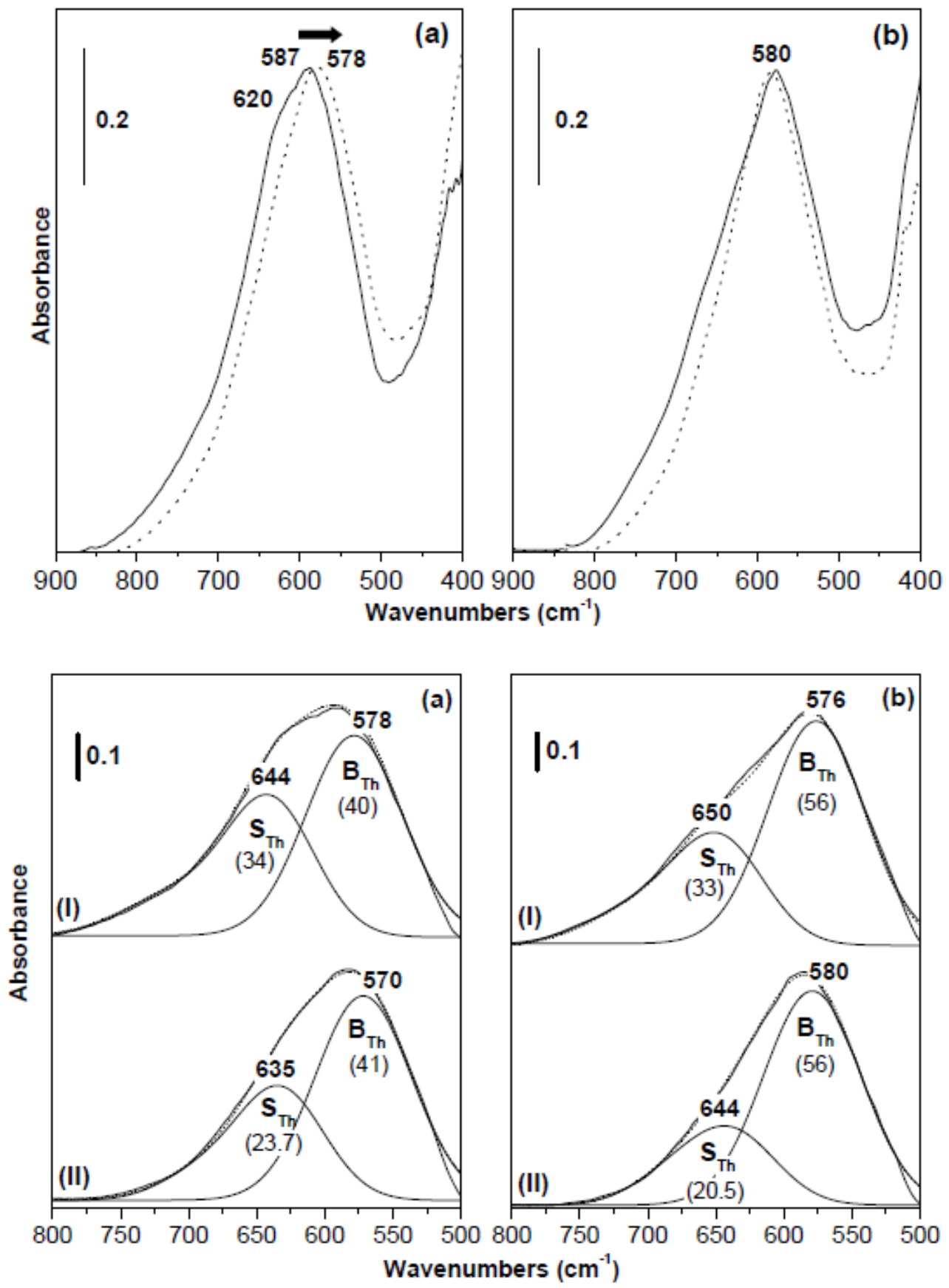

Figure 3. (Top): FTIR spectra in the $900-400 \mathrm{~cm}^{-1}$ range of $\mathrm{KBr}$ pellets of CF450 [section (a)] and CF750 [section (b)]. Solid-line curves: calcined samples. Dotted curves: FTIR spectra of catalysts first completely reduced by contact with methanol at $420^{\circ} \mathrm{C}$ and then reoxidized with steam at $420^{\circ} \mathrm{C}$.

(Bottom): Band-resolved spectra in the $800-500 \mathrm{~cm}^{-1}$ range relative to $\mathrm{CF} 450$ [section (a)] and CF750 [section (b)]. Solid-line complete spectra are the reconstructed ones, whereas broken-line 
traces are the experimental spectra. The numbers in brackets represent the integrated absorbance $\left(\mathrm{cm}^{-1}\right)$ of the individual spectral components. Spectral sets I: calcined samples. Spectral sets II: catalysts first completely reduced by contact with methanol at $420^{\circ} \mathrm{C}$ and then reoxidized with steam at $420^{\circ} \mathrm{C}$. 
FIGURE 4
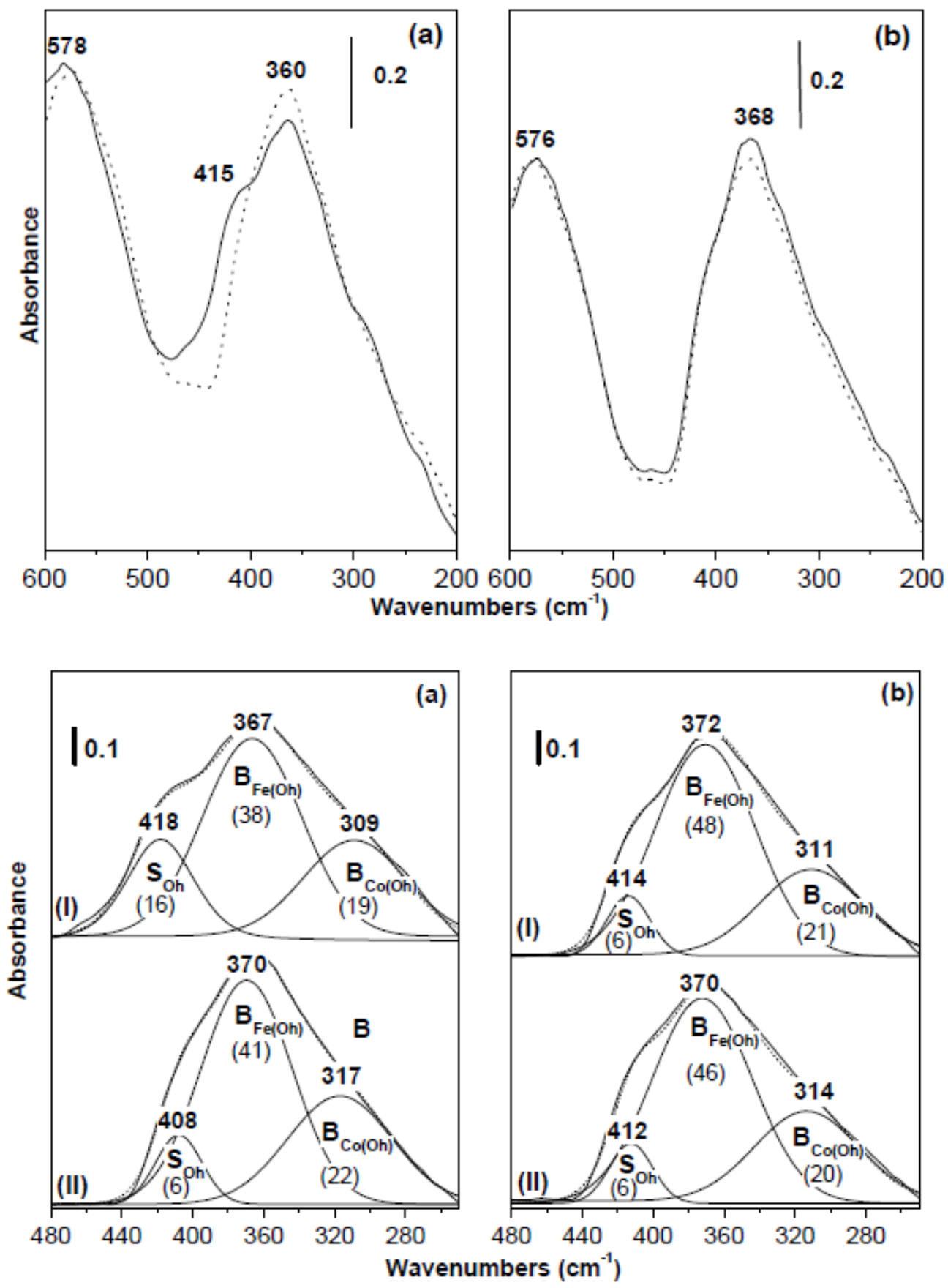

Figure 4. (Top): FTIR spectra in the $600-200 \mathrm{~cm}^{-1}$ range of paraffin wax pellets of CF450 [section (a)] and CF750 [section (b)]. Solid-line curves: calcined samples. Dotted curves: FTIR spectra of catalysts first completely reduced by contact with methanol at $420^{\circ} \mathrm{C}$ and then reoxidized with steam at $420^{\circ} \mathrm{C}$.

(Bottom): Band-resolved spectra in the $480-250 \mathrm{~cm}^{-1}$ range relative to CF450 [section (a)] and CF750 [section (b)]. Solid-line complete spectra are the reconstructed ones, whereas broken-line 
traces are the experimental spectra. The numbers in brackets represent the integrated absorbance $\left(\mathrm{cm}^{-1}\right)$ of the individual spectral components. Spectral sets I: calcined samples. Spectral sets II: catalysts first completely reduced by contact with methanol at $420^{\circ} \mathrm{C}$ and then reoxidized with steam at $420^{\circ} \mathrm{C}$. 
FIGURE 5
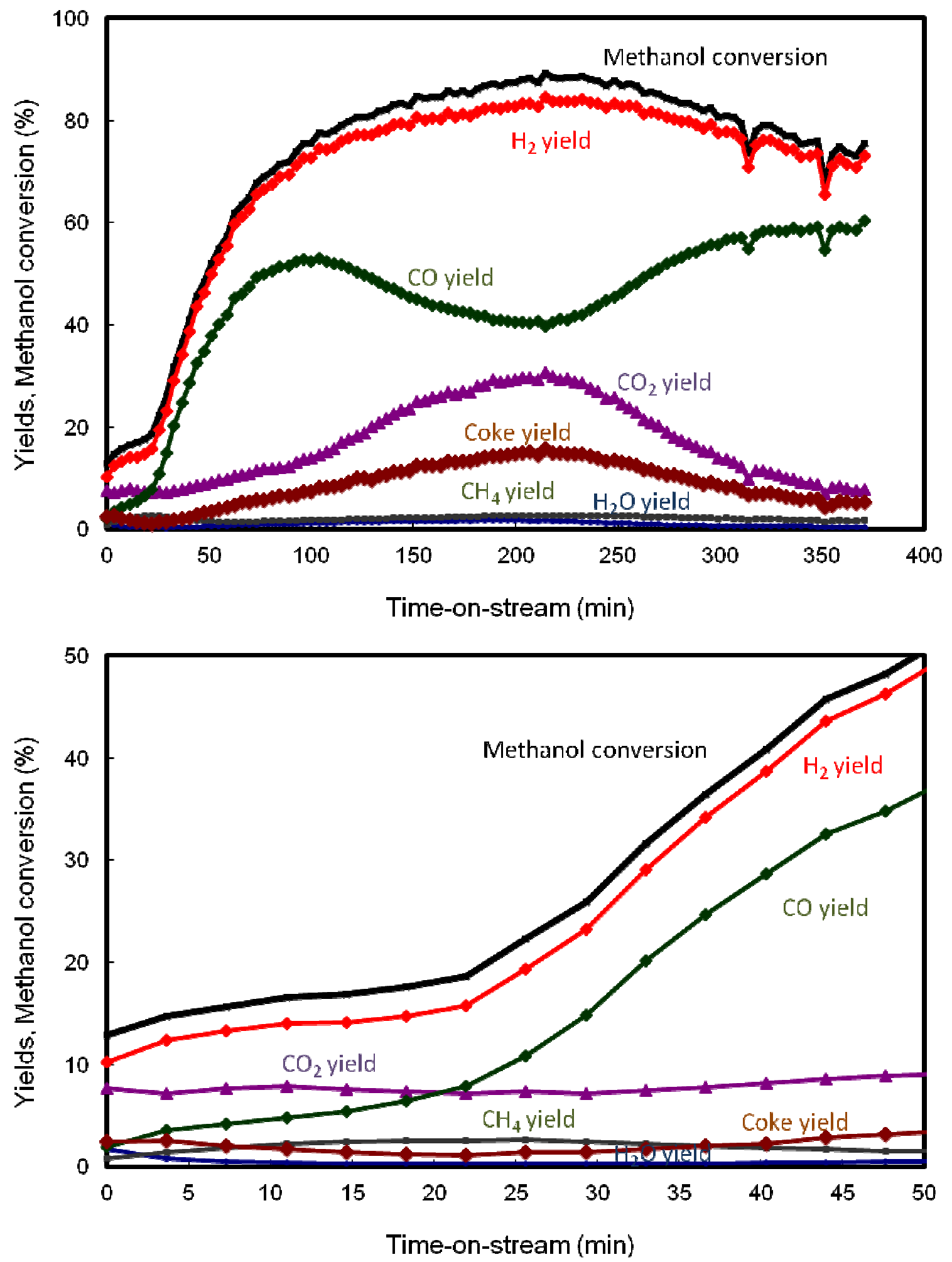

Figure 5. (Top) Methanol conversion and yields of products in function of the reaction time for catalyst CF450. Feed composition: $15.6 \mathrm{~mol} \%$ methanol, remainder $\mathrm{N}_{2}$; overall contact time $0.2 \mathrm{~s}$; temperature $300^{\circ} \mathrm{C}$. (Bottom) Detail of the first 50 min reaction time. 
FIGURE 6

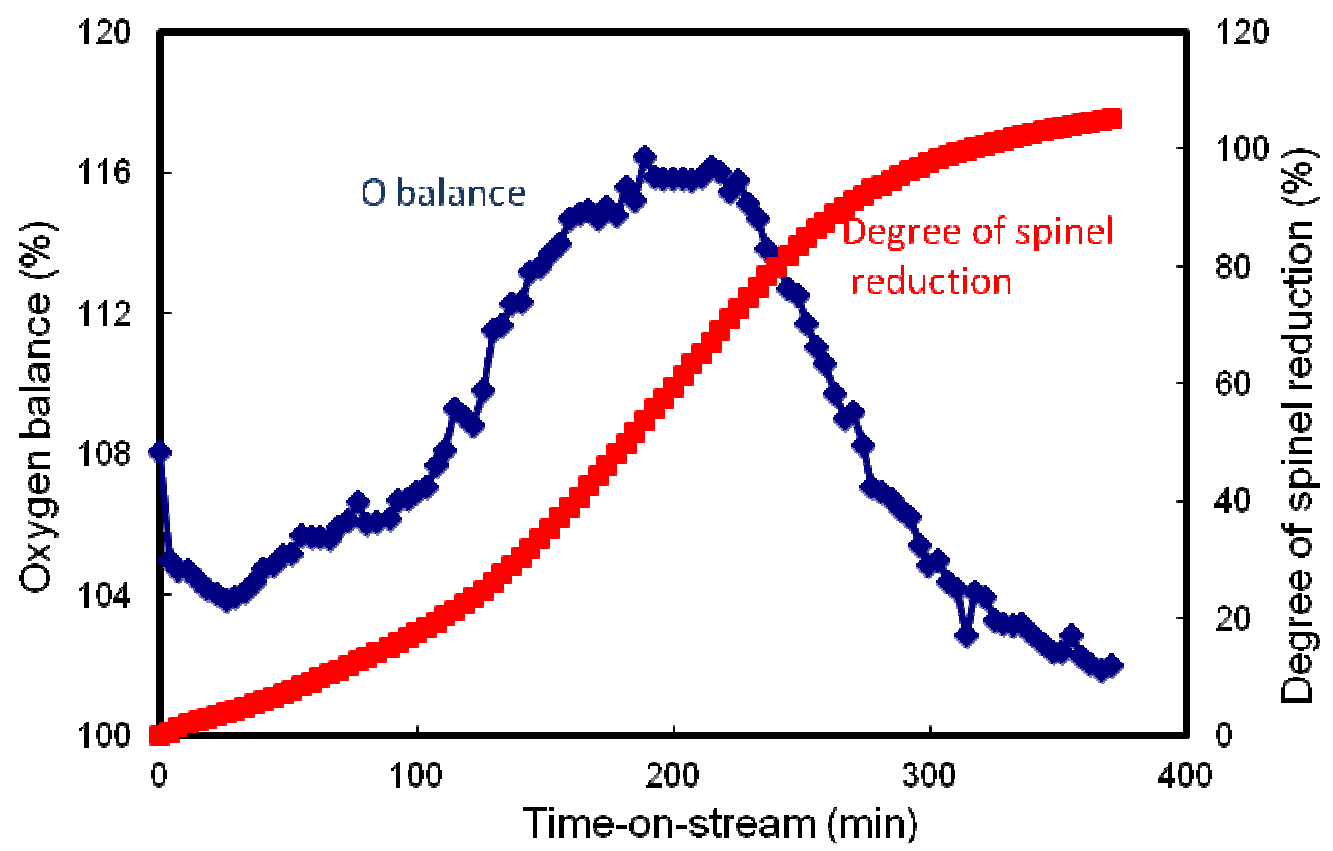

Figure 6. $\mathrm{O}$ balance and calculated spinel reduction degree as a function of reaction time. Conditions and catalyst as in Figure 5. 
FIGURE 7
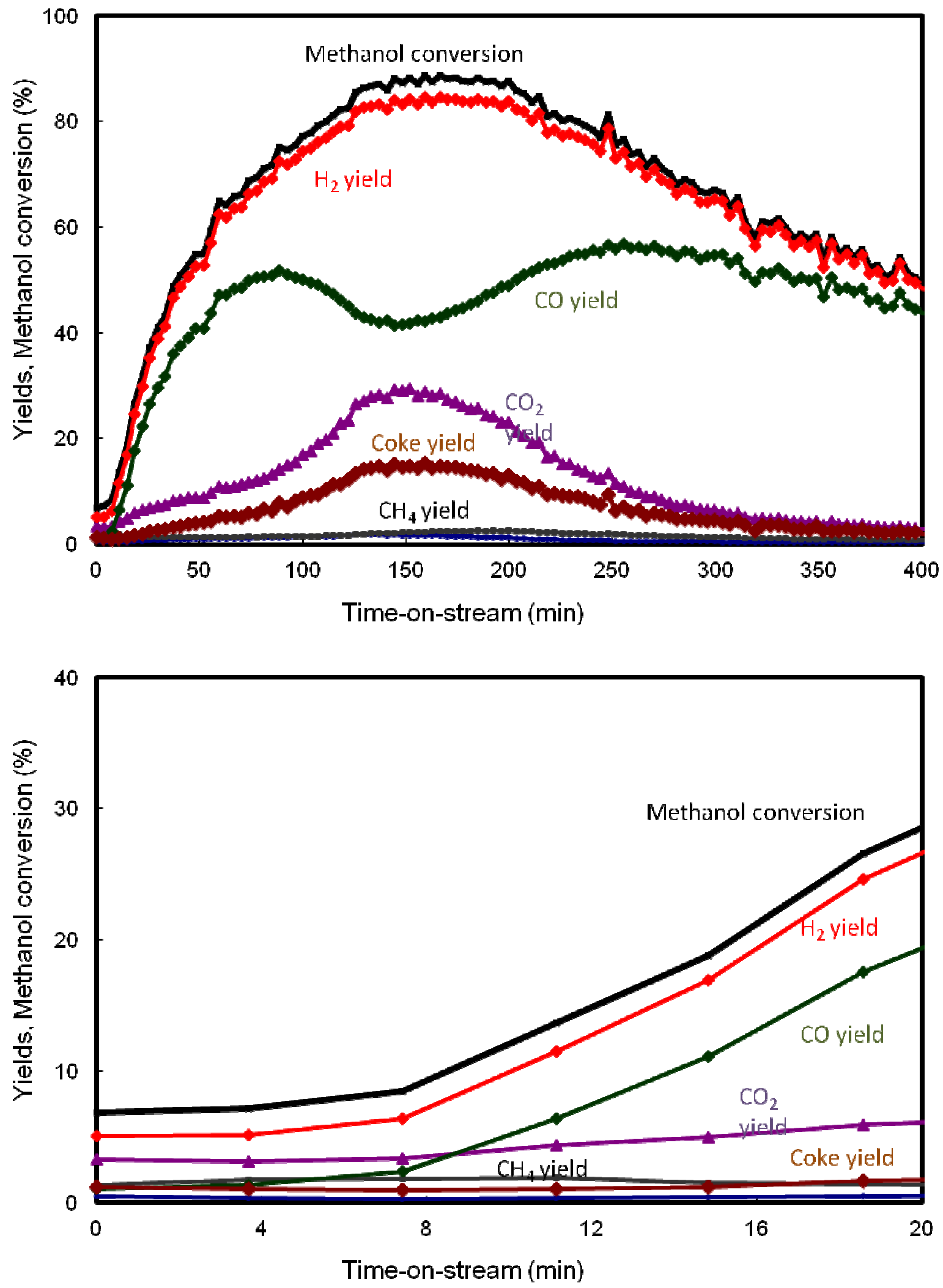
Figure 7. (Top) Methanol conversion and yields of products as a function of the reaction time for catalyst CF750. Feed composition: $15.6 \mathrm{~mol} \%$ methanol, remainder $\mathrm{N}_{2}$; overall contact time $0.2 \mathrm{~s}$; temperature $300^{\circ} \mathrm{C}$. (Bottom) Detail of the first 20 min reaction time.

\section{FIGURE 8}

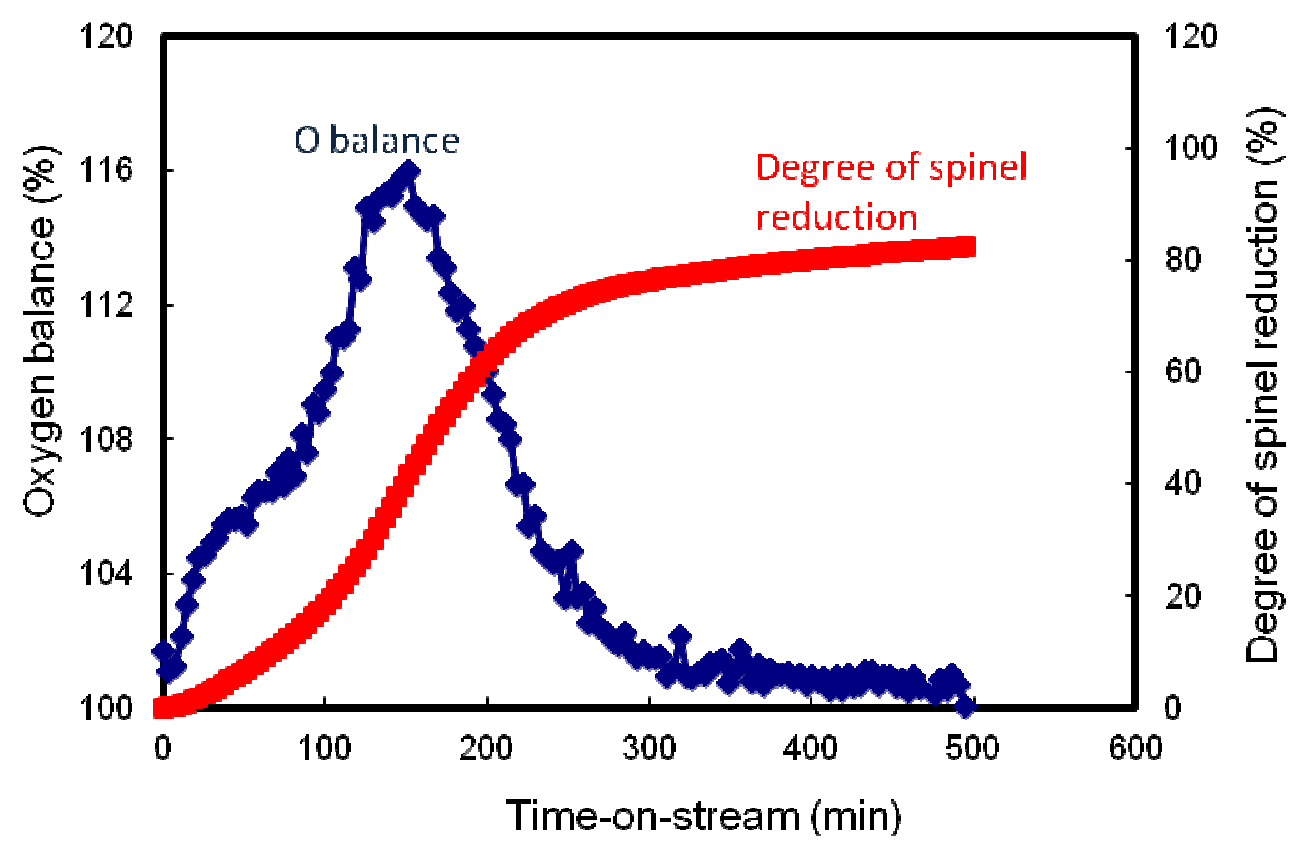

Figure 8. O balance and calculated spinel reduction degree as a function of reaction time. Conditions and catalyst as in Figure 7. 
FIGURE 9
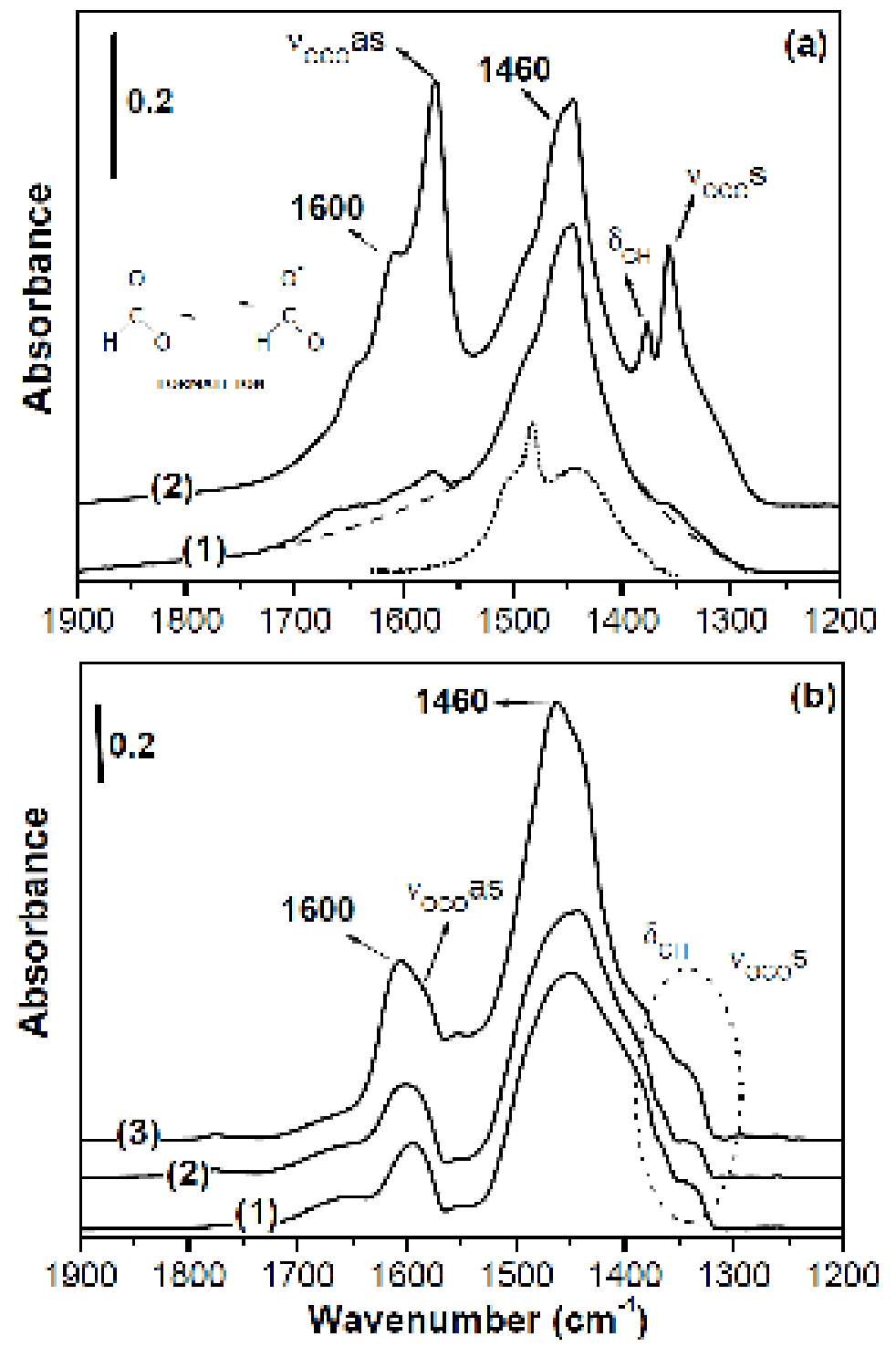

Figure 9. Absorbance differential spectra, normalized against the spectrum of the starting sample, of CF450 [section (a)] and of CF750 [section (b)] activated in vacuo at $350^{\circ} \mathrm{C}$, after methanol contact at: BT [curves (1)], $150^{\circ} \mathrm{C}$ [curves (2)], and $250^{\circ} \mathrm{C}$ [curve (3)]. The dotted-line trace refers to 80 Torr of methanol on pure silica (Aerosil 200) activated at $150^{\circ} \mathrm{C}$. 
FIGURE 10
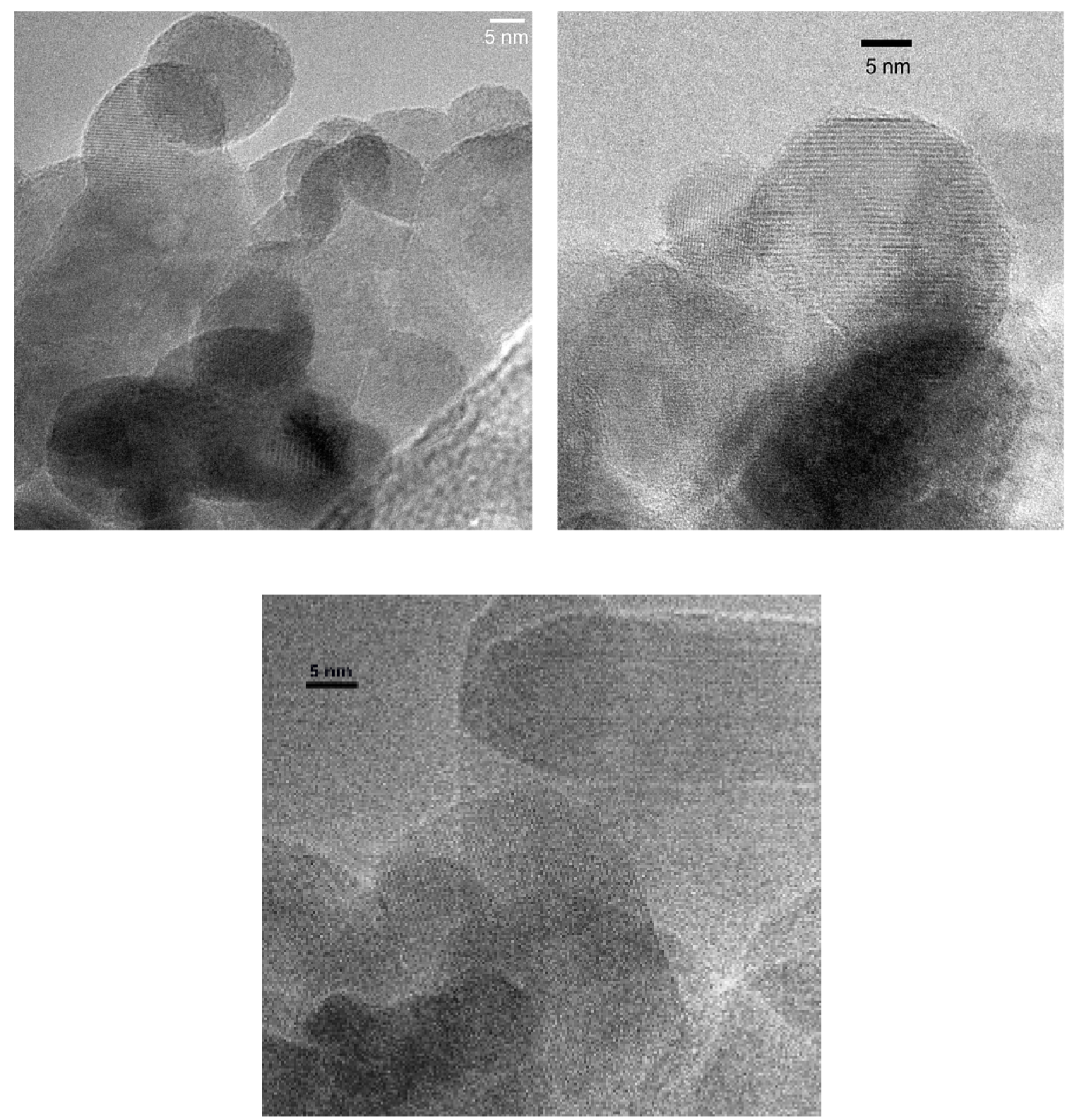

Figure 10. TEM images of used CF450 (top sections) and CF750 (bottom section). 
FIGURE 11
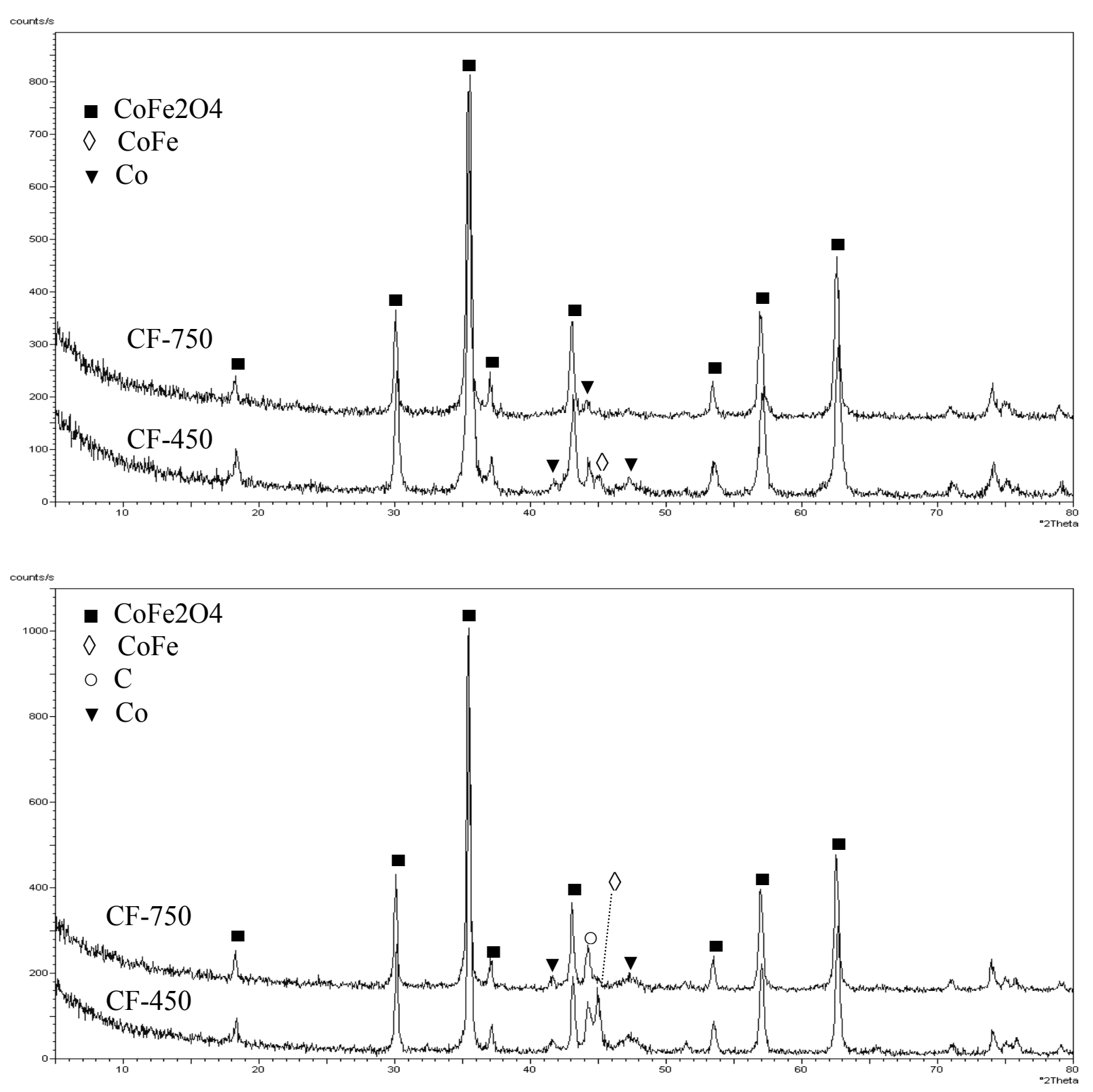

Figure 11. XRD patterns of CF450 and CF750 samples after reduction with methanol at $420^{\circ} \mathrm{C}$ for $30 \mathrm{~min}\left(\begin{array}{lll}\tau & 1 & \mathrm{~s}\end{array}\right)$ and then oxidation with steam at $420^{\circ} \mathrm{C}$ (Top Figure), and after reduction with methanol at $420^{\circ} \mathrm{C}$ for $180 \mathrm{~min}(\tau 1 \mathrm{~s})$ and oxidation with steam at $420^{\circ} \mathrm{C}$ (Bottom Figure). 
FIGURE 12

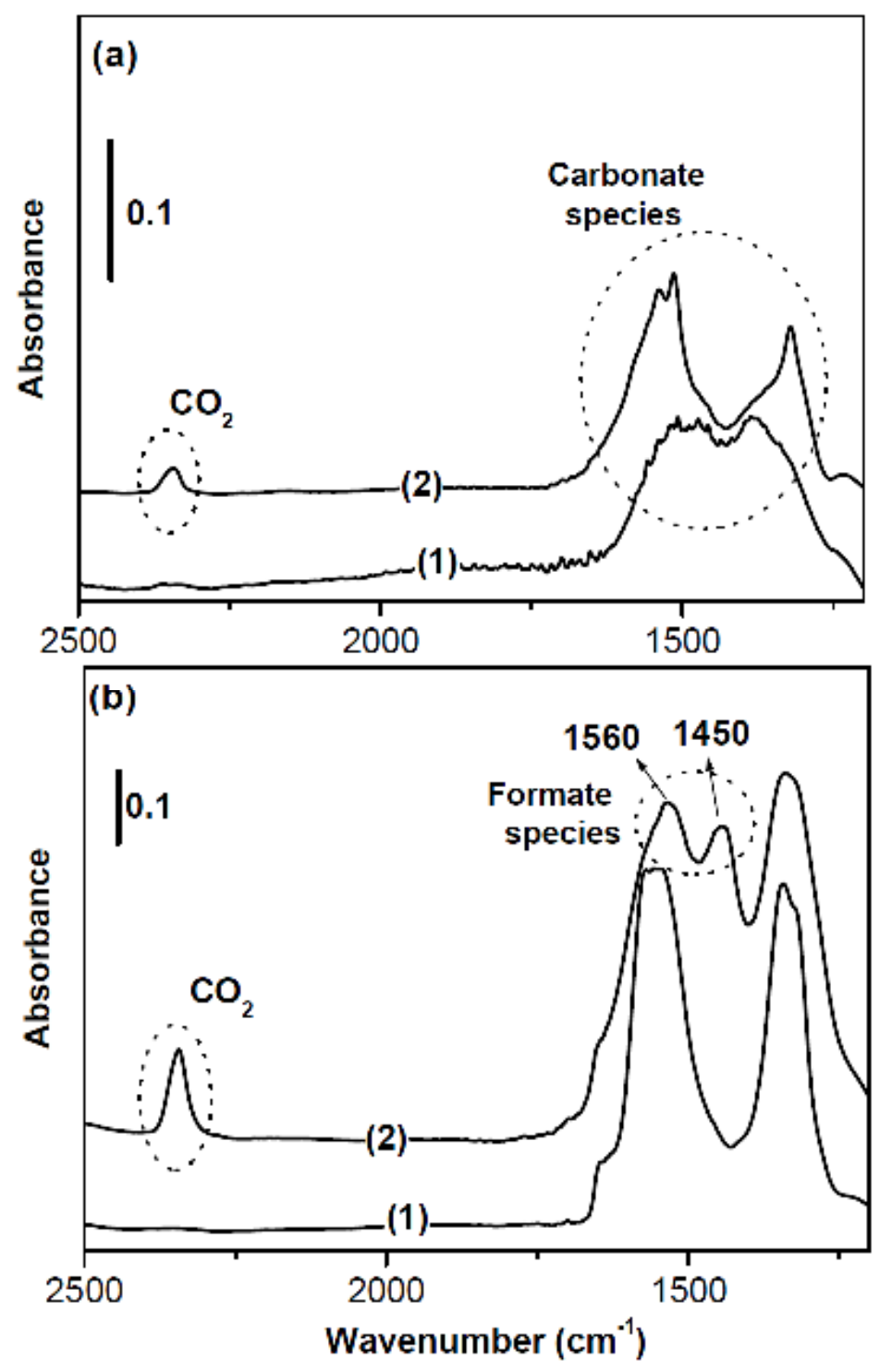

Figure 12. Absorbance spectra of CF-450 [section (a)] and CF-750 [section (b)] after activation in vacuo of the starting sample at $350^{\circ} \mathrm{C}$ [curves (1)], and oxidation at $350^{\circ} \mathrm{C}$ in $\mathrm{O}_{2}$ atmosphere of the samples reduced with methanol [curves (2)]. 